\title{
Illuminating and Sniffing Out the Neuromodulatory Roles of Dopamine in the Retina and Olfactory Bulb
}

\author{
Kirill S. Korshunov ${ }^{1,2}$, Laura J. Blakemore ${ }^{1,2}$ and Paul Q. Trombley1,2* \\ ${ }^{1}$ Department of Biological Science, Florida State University, Tallahassee, FL, United States, ${ }^{2}$ Program in Neuroscience, \\ Florida State University, Tallahassee, FL, United States
}

In the central nervous system, dopamine is well-known as the neuromodulator that is involved with regulating reward, addiction, motivation, and fine motor control. Yet, decades of findings are revealing another crucial function of dopamine: modulating sensory systems. Dopamine is endogenous to subsets of neurons in the retina and olfactory bulb $(\mathrm{OB})$, where it sharpens sensory processing of visual and olfactory information. For example, dopamine modulation allows the neural circuity in the retina to transition from processing dim light to daylight and the neural circuity in the $\mathrm{OB}$ to regulate odor discrimination and detection. Dopamine accomplishes these tasks through numerous, complex mechanisms in both neural structures. In this review, we provide an overview of the established and emerging research on these mechanisms

Edited by:

Wallace B. Thoreson,

University of Nebraska Medical

Center, United States

Reviewed by:

Christophe P. Ribelayga,

The University of Texas Health

Science Center at Houston,

United States

Claire Cheetham,

University of Pittsburgh, United States

${ }^{*}$ Correspondence:

Paul Q. Trombley

ptrombley@fsu.edu

Specialty section:

This article was submitted to

Cellular Neurophysiology,

a section of the journa

Frontiers in Cellular Neuroscience

Received: 26 May 2020 Accepted: 04 August 2020

Published: 31 August 2020

Citation:

Korshunov KS, Blakemore LJ and

Trombley PQ (2020) Illuminating

and Sniffing Out the Neuromodulatory

Roles of Dopamine in the Retina

and Olfactory Bulb.

Front. Cell. Neurosci. 14:275.

doi: 10.3389/fncel.2020.00275 and describe similarities and differences in dopamine expression and modulation of synaptic transmission in the retinas and OBs of various vertebrate organisms. This includes discussion of dopamine neurons' morphologies, potential identities, and biophysical properties along with their contributions to circadian rhythms and stimulus-driven synthesis, activation, and release of dopamine. As dysregulation of some of these mechanisms may occur in patients with Parkinson's disease, these symptoms are also discussed. The exploration and comparison of these two separate dopamine populations shows just how remarkably similar the retina and OB are, even though they are functionally distinct. It also shows that the modulatory properties of dopamine neurons are just as important to vision and olfaction as they are to motor coordination and neuropsychiatric/neurodegenerative conditions, thus, we hope this review encourages further research to elucidate these mechanisms.

Keywords: dopamine, vision, olfaction, retina, olfactory bulb, circadian rhythms, biophysical properties, Parkinson's disease

Abbreviations: 6-OHDA, 6-hydroxydopamine; AC, amacrine cell; cAMP, cyclic adenosine monophosphate; $\mathrm{D}_{1} \mathrm{R}$, dopamine receptor $1 ; \mathrm{D}_{2} \mathrm{R}$, dopamine receptor 2; $\mathrm{D}_{3} \mathrm{R}$, dopamine receptor $3 ; \mathrm{D}_{4} \mathrm{R}$, dopamine receptor $4 ; \mathrm{D}_{5} \mathrm{R}$, dopamine receptor 5; DAT, dopamine transporter; EPL, external plexiform layer; ERG, electroretinogram; ETC, external tufted cell; GABA, $\gamma$-aminobutyric acid; GAD-65, glutamic acid decarboxylase 65; GAD-67, glutamic acid decarboxylase 67; GC, granule cell; $\mathrm{GCL}_{\mathrm{OB}}$, granule cell layer; $\mathrm{GCL}_{\mathrm{R}}$, ganglion cell layer; GFP, green fluorescent protein; GL, glomerular layer; HC, horizontal cell; HIOMT, hydroxyindole-O-methyltransferase; $\mathrm{I}_{\mathrm{Ca}}, \mathrm{Ca}^{2+}$ current; $\mathrm{I}_{\mathrm{H}}$, h-current; $\mathrm{I}_{\mathrm{K}}, \mathrm{K}^{+}$current; $\mathrm{I}_{\mathrm{Na}}, \mathrm{Na}^{+}$current; INL, inner nuclear layer; IPL, inner plexiform layer; ipRGC, intrinsically photosensitive retinal ganglion cell; JGC, juxtaglomerular cell; M/TC, mitral and/or tufted cell; MCL, mitral cell layer; NAT, serotonin $\mathrm{N}$-acetyltransferase; $\mathrm{Na}$, voltage-gated $\mathrm{Na}^{+}$channel; $\mathrm{OB}$, olfactory bulb; $\mathrm{ONL}_{\mathrm{OB}}$, olfactory nerve layer; $\mathrm{ONL}_{\mathrm{R}}$, outer nuclear layer; $\mathrm{OPL}$, outer plexiform layer; $\mathrm{PC}$, piriform cortex; PD, Parkinson's disease; PGC, periglomerular cell; PKA, protein kinase A; RGC, retinal ganglion cell; RMS, rostral migratory stream; SAC, short axon cell; SCN, suprachiasmatic nucleus; SNc, substantia nigra pars compacta; TH, tyrosine hydroxylase; VIP, vasoactive intestinal polypeptide; VMAT2, vesicular monoamine transporter 2. 


\section{INTRODUCTION}

The central nervous system processes various stimuli, which allow it to respond to a constantly changing environment, while also contributing to the experiences that will allow an organism to adapt and survive. A crucial component for this to occur are neuromodulators, including dopamine. Dopamine is a famous neuromodulator that is most known for its role in rewards, addiction, motor control, and, to a lesser extent, its involvement with neurogenesis, daily rhythms, and the processing of sensory information. Dopamine is a catecholamine that is derived from the amino acid tyrosine, which is converted to L-DOPA via tyrosine hydroxylase ( $\mathrm{TH}$, the rate-limiting enzyme in dopamine production); L-DOPA is then converted to dopamine via aromatic L-amino acid decarboxylase. Dopamine can also be converted to norepinephrine (via dopamine- $\beta$-hydroxylase) followed by epinephrine (via phenylephanolamine $\mathrm{N}$-methyltransferase), the other two major catecholamines of the central and peripheral nervous systems. Over the last few decades, there has been a tremendous growth in understanding of the role of dopamine in various systems, including its regulation of two of the most crucial senses for vertebrate and invertebrate organisms: vision and olfaction.

Vision arises from responding to the electromagnetic stimuli that first hit the retina, and olfaction occurs when deciphering a volatile milieu of chemical odorants that are detected by olfactory sensory neurons (OSNs) and then processed by the olfactory bulb (OB). There are 11 catecholamine-expressing nuclei in the brain (Felten and Sladek, 1983; Hökfelt et al., 1984), and the retina and OB possess their own endogenous dopamine neuron populations. In the retina, the modulatory dopamine interneurons assist the photoreceptors, and nearly all other retinal neurons, in transitioning from processing scotopic light (during the nighttime) to processing photopic light (during the daytime). In the $\mathrm{OB}$, the number of endogenous dopamine neurons may outnumber all other dopaminergic populations in the vertebrate brain (Cave and Baker, 2009). Like the retina, the dopaminergic $\mathrm{OB}$ neurons are also modulatory interneurons, which help gate certain odor stimuli and increase odor discrimination (the ability to tell one odor apart from another). The main goal of this review is to explore the dopamine neuron populations in the retina and $\mathrm{OB}$ and their neuromodulatory mechanisms. To provide the most comprehensive view of these neurons, we also explore their identities and morphologies, their daily rhythms, activity-dependent expression, biophysical properties, and the potential disruption of their neuromodulatory mechanisms in neurodegenerative diseases such as Parkinson's disease (PD). These findings also provide insight into the many remarkable similarities and differences between the retina and $\mathrm{OB}$, thus, vision and olfaction. While we focus on the neuromodulatory roles of dopamine specifically in vertebrate organisms (fish, amphibians, turtles, reptiles, mice, rats, rabbits, cats, and people), there is also a rich literature on the activity of dopamine in various insect species, particularly in their olfactory systems (Perk and Mercer, 2006; Dacks et al., 2012; Boto et al., 2014; Lizbinski and Dacks, 2018; Sayin et al., 2018).

To understand the context of dopamine's activity, it is necessary to introduce their laminar organization and neuronal populations of the retina (Figure 1) and the $\mathrm{OB}$ (Figure 2). These structures have also been reviewed in detail elsewhere (Witkovsky, 2004; Ennis et al., 2007, 2015; Nagayama et al., 2014; Kosaka and Kosaka, 2016; Roy and Field, 2019). Light first activates the rod and cone photoreceptors in the outer retina, specifically in the outer nuclear layer $\left(\mathrm{ONL}_{\mathrm{R}}\right)$, from which rods and cones transduce and transmit light information to the excitatory bipolar cells (BCs) and the inhibitory horizontal cells $(\mathrm{HCs})$ in the outer plexiform layer (OPL). (Please note that some of the abbreviations between retinal and OB layers are the same. To avoid confusion, the identical abbreviations related to the retina will have the "R" subscript, and an "OB" subscript will be included for $\mathrm{OB}$ layers. e.g., $\mathrm{ONL}_{\mathrm{R}}$ and $\mathrm{ONL}_{\mathrm{OB}}$.) In photopic conditions, rods and certain cones activate the ON$\mathrm{BCs}$, while the OFF-BCs will activate in scotopic conditions by another subset of cones and indirectly by rods. The BCs send this light information along the inner nuclear layer (INL) to the dendrites of the retinal ganglion cells (RGCs) and a subset of RGCs called the intrinsically photosensitive retinal ganglion cells (ipRGCs). Synapses between BCs and RGCs form in the inner plexiform layer (IPL) - in the OFF portion (strata 1 and 2) for OFF-driven RGCs and in the ON portion (strata 3-5) for the ON-driven RGCs. Lastly, the transmission from BCs can be modulated by the inhibitory receptive field of the amacrine cells (ACs), either in the OFF or ON portion of the IPL. The RGCs and ipRGCs somas are in the deepest retinal layer, the ganglion cell layer $\left(G L_{R}\right)$. From there, RGCs send light information to a few dozen nuclei (Dhande and Huberman, 2014), including those in the thalamus, hypothalamus, midbrain, and visual cortex as the optic nerve.

While visual processing in the retina ends with the optic nerve, odor processing begins with the olfactory nerve. Odor transduction begins in the olfactory epithelium, where OSNs are activated by a specific chemical odorant, allowing them to send an electrical impulse to the $\mathrm{OB}$ via the olfactory nerve. The OSNs axons pass through the first layer of the $\mathrm{OB}$, the olfactory nerve layer $\left(\mathrm{ONL}_{\mathrm{OB}}\right)$, and terminate in the glomeruli of the glomerular layer (GL) where they form synapses with various $\mathrm{OB}$ neurons. Glomeruli are dense, neuropil-rich structures that are surrounded and innervated by a population of inhibitory interneurons - periglomerular cells (PGCs) and short-axon cells (SACs) - and excitatory interneurons - external tufted cells (ETCs). Collectively, these neurons are known as juxtaglomerular cells (JGCs), and they are the first neurons to have the opportunity to modulate the excitatory/glutamatergic odor signals received from the OSNs. These signals are picked up by the apical dendrites of the main output neurons of the $\mathrm{OB}$ - the mitral and tufted cells (M/TCs; these neurons are often abbreviated together due to their similar morphologies and proximity to one another, often making them difficult to differentiate in many studies). The processes and cell bodies of M/TCs span a number of OB layers, ranging from apical dendrites extending to the GL, to 


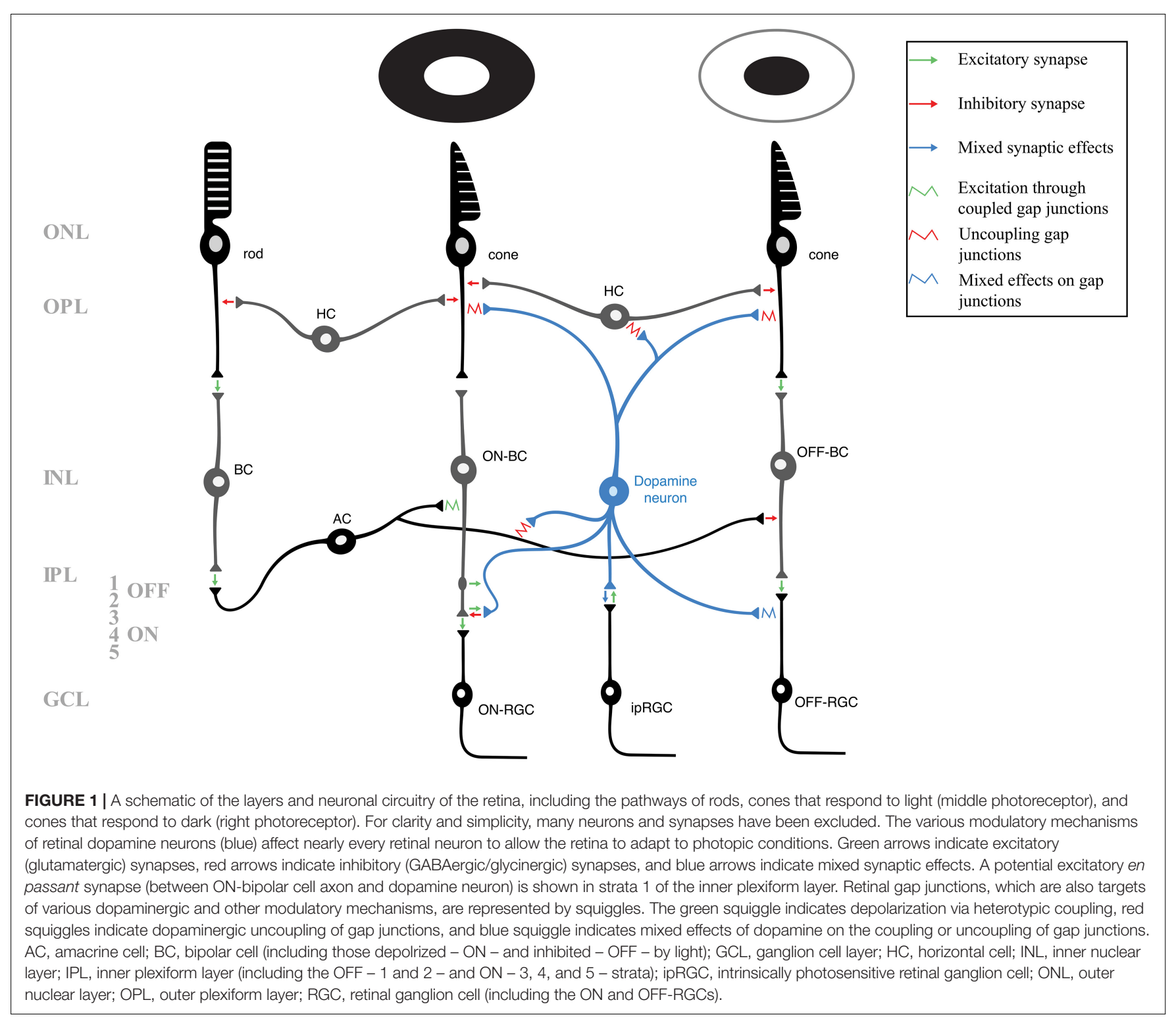

tufted cells' somas localized to the external plexiform layer (EPL), and mitral cells' somas localized deeper in the mitral cell layer (MCL). Further modulation of odor information occurs at dendrodendritic synapses between lateral dendrites of M/TCs and dendrites of inhibitory granule cells (GCs) in the EPL. Axons of the M/TCs extend to the granule cell layer $\left(\mathrm{GCL}_{\mathrm{OB}}\right)$ and then send signals from the $\mathrm{OB}$, via the lateral olfactory tract, to various regions of the olfactory cortex and the limbic system.

Dopaminergic neurons in the retina and $\mathrm{OB}$ are mainly localized to the INL and the GL, respectively (Witkovsky, 2004; Ennis et al., 2007, 2015; Nagayama et al., 2014; Roy and Field, 2019). Their strategic localization allows them to affect sensory processing through various neuromodulatory mechanisms by activating specific dopamine receptors. Dopamine receptors are G-protein coupled receptors that fall into two categories: $D_{1}$ - and $D_{2}$-like receptors. The $D_{1}$ receptor family, which includes $D_{1}$ and $D_{5}$ receptors $\left(D_{1} R\right.$ and $D_{5} R$, respectively), acts to increase protein kinase A (PKA) activity by activating adenylyl cyclase via $G \alpha_{S}$, which then increases cAMP production, and thus, the phosphorylation activity of PKA (Missale et al., 1998). The $\mathrm{D}_{2}$ receptor family, which includes $D_{2}, D_{3}$, and $D_{4}$ receptors $\left(D_{2} R\right.$, $\mathrm{D}_{3} \mathrm{R}$, and $\mathrm{D}_{4} \mathrm{R}$, respectively), works in the opposite manner, where they inhibit the adenylyl cyclase/cAMP/PKA pathway via the $G \alpha_{i}$ protein (Missale et al., 1998). The $D_{1}, D_{2}$, and $D_{4} R s$ are found within the retinas of various species (Nguyen-Legros et al., 1996, 1997; Veruki and Wässle, 1996; Jackson et al., 2009; Li et al., 2013). The $\mathrm{D}_{3} \mathrm{R}$ gene (Dr3d) is not found in the retina, and the $\mathrm{D}_{5} \mathrm{R}$ gene $(D r 5 d)$, while apparently present, does not have a known protein expression or function in the retina (Jackson et al., 2009). The OBs of various species express $D_{1}$ Rs and $D_{2}$ Rs (Levey et al., 1993; Coronas et al., 1997; Duchamp-Viret et al., 1997; Koster et al., 1999; Gutièrrez-Mecinas et al., 2005; Rodrigues et al., 2014), but the presence of $D_{3}-D_{5}$ Rs is not known. 


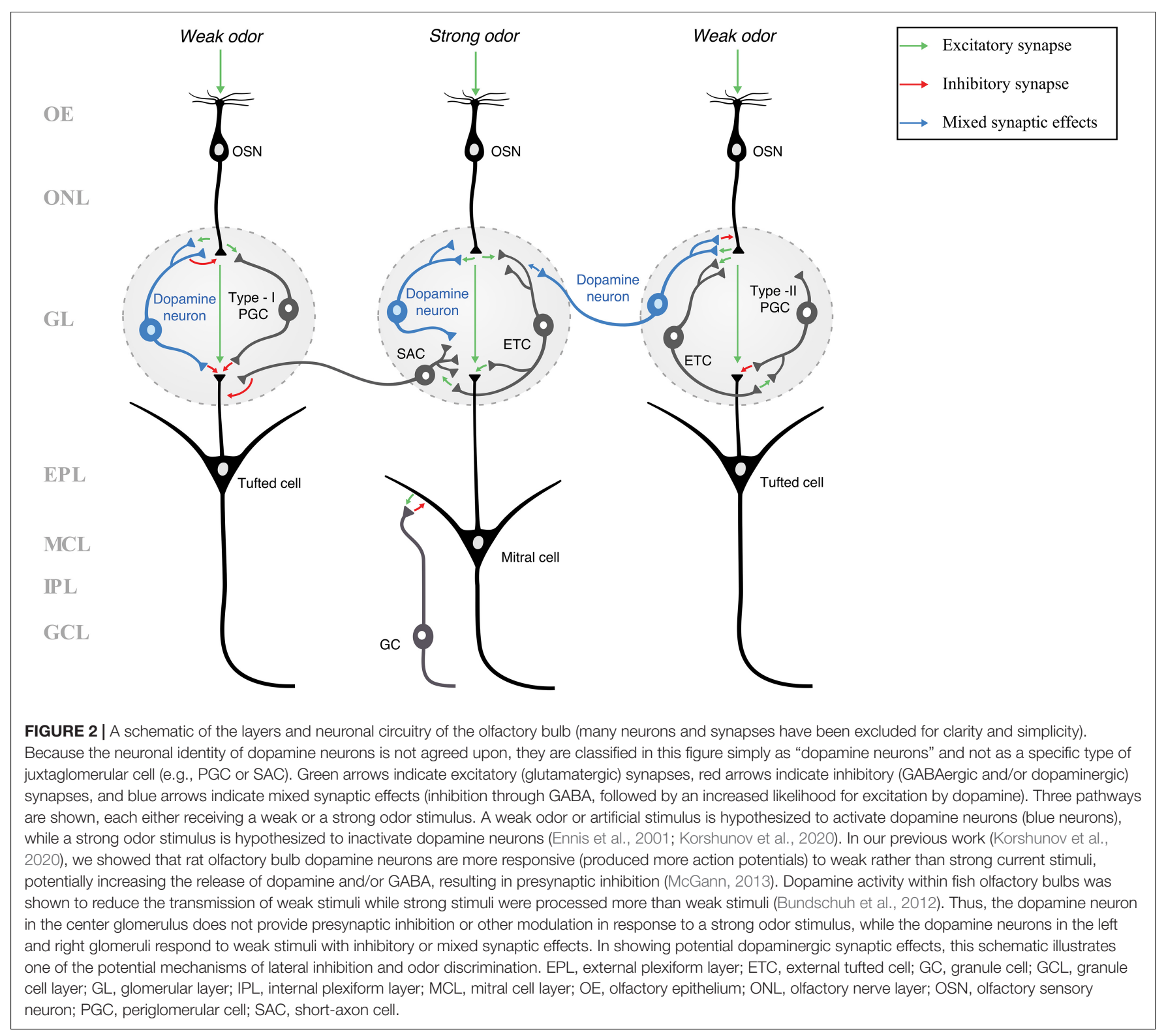

We begin this review by first describing the morphology and neuronal identity of retinal and $\mathrm{OB}$ dopamine neurons.

\section{MORPHOLOGY AND NEURONAL IDENTITY}

\section{Retinal Dopamine Neurons}

The endogenous dopamine neurons of the retina, found within the INL, project their processes through the ON and OFF strata of the IPL and are most commonly referred to as ACs (Witkovsky, 2004; Roy and Field, 2019). There are many subpopulations of the retinal ACs (Roy and Field, 2019), with most recent estimates being around 140 cell types in the mouse (Yan et al., 2020), and the putative dopaminergic neurons were calculated to only comprise $0.08 \%$ of all of the mammalian ACs (Jeon et al., 1998). However, dopamine neurons are also sometimes classified as interplexiform cells, because their processes can extend to the outer retina (Versaux-Botteri et al., 1984; Wulle and Schnitzer, 1989; Umino and Dowling, 1991; Harsanyi and Mangel, 1992; Witkovsky et al., 2000). A similar identity crisis is associated with the dopaminergic neurons in the $\mathrm{OB}$ (discussed in section "Olfactory Bulb Dopamine Neurons"). To avoid any nomenclatural confusion, we will simply refer to these as retinal and $\mathrm{OB}$ dopamine neurons.

In the retina, the catecholamine/TH-expressing neurons can be divided into two groups: Type- 1 and Type- 2 cells. The Type- 1 cells have a larger soma than Type-2s, they are localized within the INL, and have a high expression of TH (Versaux-Botteri et al., 1984; Mariani and Hokoc, 1988; Tauchi et al., 1990; Wang et al., 1990; Zhang et al., 2004). Soma sizes of Type-1 cells appear consistent across mammalian species: roughly 12.5 to $15.5 \mu \mathrm{m}$ in 
cats (Wang et al., 1990) and $13.5 \mu \mathrm{m}$ in mice (Zhang et al., 2004). Type- 1 cells have thick and thin processes that originate from the soma and extend toward stratum 1 of the IPL, and they also have fine processes that extend toward the OPL (Zhang et al., 2004). Type- 2 cells are distinctly different from the Type- 1 cells. Type2 cells have smaller somas, are often more widespread in their localization (they are found in the INL, IPL, and $G_{C L}$ ), they are more numerous, and have a dimmer staining for $\mathrm{TH}$ than Type-1 cells (Versaux-Botteri et al., 1984; Mariani and Hokoc, 1988; Tauchi et al., 1990; Wang et al., 1990; Zhang et al., 2004). Type- 2 cell processes arborize in the middle of the IPL (Mariani and Hokoc, 1988). During development, the number of Type1 cells $(\sim 4,000$ in the cat's retina) remains the same before and after eyes open, with their dendritic appendages growing until postnatal day 13 (when cats' eyes begin to open) (Wang et al., 1990). Conversely, the smaller Type-2 cells become dimmer and lose $\mathrm{TH}$ expression throughout development, and their density also appears to drop from $\sim 40,000$ neurons at postnatal day 1 to $\sim 7,400$ neurons when eyes open at postnatal day 13, although this is likely due to decreased TH expression rendering them undetectable (Wang et al., 1990). Thus, these two types of catecholaminergic retinal neurons may serve different roles in modulation of retinal neurons, as well as playing some role during development. Presently, only the Type- 1 cell is considered to be dopaminergic.

Some recent and classic studies comment on the consistently low expression of $\mathrm{TH}$ in Type- 2 cells, or describe simply not being able to label them with the $\mathrm{TH}$ antibody in transgenic animals (Versaux-Botteri et al., 1986; Zhang et al., 2004; Contini et al., 2010). Zhang et al. (2004) noted that a reason for this could be that the $\mathrm{TH}$ promoter was more sensitive than the antibody used in detecting TH. It was speculated that the Type- 2 cells are actually epinephrine neurons (Versaux-Botteri et al., 1986), which may be present in the mammalian retina (Hadjiconstantinou et al., 1983). Also, Type-2 cells did not appear to have an axon, while Types-1 cells did (Zhang et al., 2004). Consistent with the idea of there being at least two types of retinal $\mathrm{TH}$ neurons, a recent study found that a specific subset of ACs (C25) express TH at higher levels than other types of ACs (Yan et al., 2020). Additionally, these C25 TH neurons (presumably the Type-1 dopamine neurons) expressed two isoforms of the precursor enzyme to $\gamma$-amino butyric acid (GABA): high levels of glutamic acid decarboxylase-67 (GAD-67) and moderate levels of GAD-65 (Yan et al., 2020). These data provide the general distinction that Type-1 cells are dopaminergic, while the nature of the Type- 2 catecholamine cells remains to be elucidated. While this may give the impression that Type-1 retinal dopamine neurons are a homogenous population, they were later differentiated by their different stimulus-dependent and biophysical activities (discussed in section "Light-Driven Activation and Synthesis of Retinal Dopamine" and section "The Spiking Profile of Retinal Dopamine Neurons," respectively).

\section{Olfactory Bulb Dopamine Neurons}

Localized almost entirely to the GL, there are $\sim 100,000-$ 150,000 dopamine neurons in the $\mathrm{OB}$ of the adult rat and $\sim 89,000$ dopamine neurons in the $\mathrm{OB}$ of the adult mouse, which correspond to $10-16 \%$ of all JGCs being dopaminergic (McLean and Shipley, 1988; Panzanelli et al., 2007; ParrishAungst et al., 2007). Dopamine neurons are also found in the OBs of humans (Smith et al., 1993; Alizadeh et al., 2015). These dopamine neurons, subtypes of PGCs and GCs, are continuously generated in the subventricular zone (SVZ) and migrate to the OB throughout adulthood (McLean and Shipley, 1988; Gross, 2000; Lledo et al., 2006; Merkle et al., 2007; Whitman and Greer, 2007; Pignatelli et al., 2009; Galliano et al., 2018). The implication of these adult-born neurons is that they could be used as therapeutic treatment for PD (Baker et al., 2001; Alizadeh et al., 2019).

While the retinal dopamine neurons are mostly classified as ACs (and, to a lesser extent, as interplexiform cells or interplexiform ACs), the identity of $\mathrm{OB}$ dopamine neurons is less settled. Classically, these neurons were identified as ETCs (Halász et al., 1981; Davis and Macrides, 1983). However, this classification is no longer used because ETCs are glutamatergic and excitatory (Hayar et al., 2004), while OB dopamine neurons (like retinal dopamine neurons: Wulle and Wagner, 1990; Contini and Raviola, 2003; Hirasawa et al., 2009; Yan et al., 2020) express GAD-67 and GABA and are thus inhibitory (Kosaka et al., 1985, 1987, 1995; Gall et al., 1987; Baker, 1990; Wilson and Wood, 1992; Kosaka and Kosaka, 2007; Maher and Westbrook, 2008; Kiyokage et al., 2010; Borisovska et al., 2013; Liu et al., 2013). Currently, OB dopamine neurons are typically classified as either PGCs or SACs.

The PGC is the most ubiquitous and widely used classification of OB DA neurons (Kosaka and Kosaka, 2011, 2016). PGCs are the most numerous and smallest of the JGCs - with somas ranging from 5 to $10 \mu \mathrm{m}$ (Ennis et al., 2007; Nagayama et al., 2014). Like the retinal catecholamine neurons, these PGCs consist of at least two types: Type-1 and Type-2 PGCs. The putative PGCs that receive synaptic input from OSNs and expresses TH are classified as the Type-1 PGCs (Kosaka et al., 1997, 1998; Kosaka and Kosaka, 2004, 2007). The PGCs that do not receive input from OSNs and do not express $\mathrm{TH}$, but do express $\mathrm{Ca}^{2+}$-binding proteins such as calretinin, calbindin, and parvalbumin, are classified as Type-2 PGCs (Kosaka et al., 1997, 1998; Kosaka and Kosaka, 2004, 2005). Our own immunolabeling results (unpublished data) confirm that rat $\mathrm{OB}$ dopamine neurons do not express calretinin. Thus, if a subset or all of the OB dopamine neurons are the PGCs, then they may be the Type-1, but not the Type 2 PGCs.

In the previous decade, it was common to identify OB dopamine neurons as SACs, largely due the fact these neurons have long, interglomerular (contacting multiple neighboring and distant glomeruli) axonic processes (Kiyokage et al., 2010; Liu et al., 2013, 2016). In fact, dopamine neurons are the most common source of interglomerular projections in the $\mathrm{OB}$ (Kosaka and Kosaka, 2008), with some projections spanning up to $1 \mathrm{~mm}$ (Aungst et al., 2003; Kiyokage et al., 2010). These neurons' dendritic processes can also project to and ramify in 7 to 39 glomeruli (Kiyokage et al., 2010). However, there is argument that $\mathrm{OB}$ dopamine neurons cannot all be SACs because most of these neurons do not have an axon (Chand et al., 2015; Galliano et al., 2018), and their dendritic branching is more attributed to 
the PGC and not the SAC morphology (Kosaka and Kosaka, 2009, 2011, 2016; Kosaka et al., 2019).

While the identity of the dopaminergic OB JGCs remains to be determined, there is near universal agreement that these neurons fall into at least two subpopulations. These subpopulations are typically differentiated by a bimodal distribution of soma size and diameter (Pignatelli et al., 2005; Kosaka and Kosaka, 2007, 2008, 2009, 2011), by the presence or absence of an axon (Chand et al., 2015; Galliano et al., 2018), and by the difference in their biophysical properties, such as action potential spiking and the $\mathrm{Na}^{+}$current $\left(\mathrm{I}_{\mathrm{Na}}\right)$ (Korshunov et al., 2020). However, the $\mathrm{OB}$ dopamine populations may be more heterogenous than simply two subtypes. A recent study by Kosaka et al. (2019) presented evidence that there may be four or more different types of dopaminergic JGCs. These include the "Large PGCs," which are axonic and have dendrites with few spines that would tuft in one or several glomeruli, which may be the subpopulation that was previously classified as SACs (Kosaka et al., 2019). The neurons classically thought of as being PGCs were redefined as the "Small PGCs," which had small soma diameters, typically lacked an axon, and had 1-4 spiny dendritic processes that could tuft in as many glomeruli (Kosaka et al., 2019). The "Transglomerular" neurons displayed a dendrite that spanned up to 6 glomeruli, and the "Incrusting" cells are the smaller dopamine neurons that had a mostly non-spiny dendrite spanning the periphery of its glomerulus (Kosaka et al., 2019). Furthermore, some of the examined dopamine neurons did not fit into any of the above categories, leaving them unclassified (Kosaka et al., 2019).

\section{CIRCADIAN RHYTHMS}

Daily rhythms that oscillate in a 24-h period are called circadian rhythms (Latin for "about a day"). Circadian rhythms regulate nearly all biological functions, including gene transcription, metabolism and body temperature, hunger, neuronal activities, and many others, by synchronizing them to a specific time of the day. Zeitgebers, including light and temperature, are the external cues that entrain (set phase to) these rhythms. Once thought of as the master circadian pacemaker, the suprachiasmatic nucleus (SCN) of the hypothalamus sets the rhythmicity of the brain and body by receiving light signals from the melanopsin-expressing ipRGCs via the retinohypothalamic tract (Mohawk et al., 2012). While the SCN is capable of maintaining rhythmicity through a transcriptional inhibitory feedback loop of the canonical "clock" genes/proteins (discussed further, but see Mohawk et al., 2012 for more details), it is now thought that peripheral clocks in cellular populations are capable of operating independently as long as they receive entrainment information from zeitgebers (Husse et al., 2015). Normally functioning cellular clocks allow biological processes to correspond with the time of day (e.g., higher metabolism in the daytime/afternoon, lower body temperature during the night). Areas such as the retina and $\mathrm{OB}$ are unique because they have an "inner/autonomous clock" that can maintain rhythmicity in the absence of zeitgebers and a functioning SCN.
In this section, we explore the established and the proposed roles of retinal and OB dopamine neurons, respectively, in contributing to their circadian rhythms and inner clocks. It should also be noted that when studies describe the circadian rhythms of the animal or a tissue, that these rhythms are often recorded under constant darkness, without light acting to entrain the rhythmicity. "Diurnal" rhythms, on the other hand, are often recorded in some presence of light, typically in 12 -h light/dark cycles.

\section{Circadian Rhythms in the Retina and Dopamine's Involvement}

Given that the retina is crucial for sending signals to and entraining the SCN, it is not surprising that it is necessary for it to maintain an autonomous inner clock. Early evidence of this clock was presented in cultured amphibian and mammalian retinas, where serotonin $\mathrm{N}$-acetyltransferase (NAT, one of the key enzymes in the production of melatonin) and melatonin exhibited circadian rhythmicity (Besharse and Iuvone, 1983; Iuvone, 1986; Tosini and Menaker, 1996). In amphibian retinal cultures, circadian melatonin production is dependent on the presence of rods and cones (Cahill and Besharse, 1993), and dopamine, acting through the $\mathrm{D}_{2} \mathrm{R}$, suppressed melatonin production in these cultures (Cahill et al., 1991). This inhibitory action was confirmed to be present in mammalian retina, where the $\mathrm{D}_{2} / \mathrm{D}_{4} \mathrm{R}$, present on photoreceptors, inhibited melatonin synthesis (Nguyen-Legros et al., 1996; Tosini and Dirden, 2000). The mechanism likely involves $\mathrm{D}_{2} \mathrm{R}$ activation decreasing cAMP activity, which, in turn, decreases NAT activity and melatonin production (Iuvone, 1986). Thus, the inhibitory feedback loop between retinal melatonin and dopamine is a crucial mechanism for the maintenance of circadian rhythms in the retina (Tosini et al., 2008).

In vertebrate retinas, synthesis and activity of dopamine increase during daytime as melatonin simultaneously falls. The presence of retinal melatonin rhythms is necessary for dopamine to maintain circadian rhythms in mammalian (Doyle et al., 2002a), fish (Ribelayga et al., 2004), and reptilian retinas (Bartell et al., 2007). In contrast to results of previous studies, the rhythmicity of dopamine was found to not be dependent upon the presence of rod and cone photoreceptors, as mutant rats with degenerated photoreceptors still maintained rhythmicity of dopamine activity up to 2 weeks in constant darkness (Doyle et al., 2002b). However, this is likely due to the finding that retinal melatonin can adapt to conditions where photoreceptor functionality is lost (Tosini et al., 2008). In addition to being expressed in photoreceptors, NAT mRNA is also expressed in the inner retina (INL and $\mathrm{GCL}_{\mathrm{R}}$ ) (Liu et al., 2004) at low levels, but becomes upregulated in dystrophic retinas where photoreceptors are degenerated (Sakamoto et al., 2004). These and other mechanisms (possibly including melatonin supplied by the pineal gland) could be contingencies in order to maintain the autonomous clock of dystrophic retinas. Thus, the circadian release of retinal melatonin is needed to maintain the circadian rhythms of dopamine (Tosini et al., 2008). The relative circadian rhythms of melatonin and dopamine are summarized 
in Figure 3A. When light acts as a stimulus, it increases retinal dopamine levels above the circadian levels that would be seen in constant darkness (the response of dopamine neurons to light is discussed in section "Light-Driven Activation and Synthesis of Retinal Dopamine").

In mammals, HCs, dopaminergic and catecholaminergic ACs, and ipRGCs all possess mRNAs of the six main clock genes that regulate circadian rhythms through the inhibitory transcription/translation feedback loop: Clock, Bmall, Cryl, Cry2, Per1, and Per2 (Ruan et al., 2006). In addition, the protein CRY1 is found to be expressed in every retinal layer and CRY2 is expressed in photoreceptors (Wong et al., 2018). One study shows that these genes are most expressed within the dopaminergic neurons and are completely absent from the photoreceptors (Ruan et al., 2006). However, another study shows that these genes are expressed by and show circadian transcriptional activity in photoreceptors (Dkhissi-Benyahya et al., 2013). This discrepancy may be due to the finding that cone photoreceptors express clock proteins with circadian rhythmicity, while rod photoreceptors do not (Liu et al., 2012). Thus, the autonomous clock of the retina is present in the INL, GCL $\mathrm{G}_{\mathrm{R}}$, and likely the OPL (Witkovsky et al., 2003; Ruan et al., 2006; Dkhissi-Benyahya et al., 2013). The presence of the clock in the INL was further supported because this explanted layer still shows a rhythmic expression of the PER2 protein (Ruan et al., 2008).

All retinal dopaminergic receptors impact some aspect of circadian rhythms. Activation of $\mathrm{D}_{1}$ Rs phase-advances PER2 expression during the subjective day (when an animal is in constant darkness, its rhythms still oscillate, with certain peaks occurring during its subjective "day" and "night") and phasedelays the expression during the subjective night (Ruan et al., 2008). Activation of $D_{2} R s$, in turn, increases the activity of the BMAL1:CLOCK complex, which is then necessary to transcribe the Per1 gene in the retina (Yujnovsky et al., 2006). $\mathrm{D}_{4} \mathrm{R}$ activation modulates the rhythmic expression of another clock gene, Npas2, in RGCs, which is thought to increase daytime contrast sensitivity (ability to detect variations in light intensities) (Hwang et al., 2013), though it's not clear if RGCs themselves express the $\mathrm{D}_{4} \mathrm{R}$. In the ipRGCs, $\mathrm{D}_{2} \mathrm{R}$ activation is necessary for the regulation of the mRNA of the photopigment melanopsin (Sakamoto et al., 2005).

\section{Circadian Rhythms in the Olfactory Bulb and Dopamine's Potential Involvement}

Analogous to the retina, the $\mathrm{OB}$ also possess its own autonomous inner clock. Perhaps the earliest evidence of this was observed when cultured neurons from rat OBs exhibited strong rhythmic expression of the Perl gene, without input from the SCN, which peaked during the nighttime (Abe et al., 2002). These results were strengthened by the persistence of Per1 rhythmicity in the presence of constant light and an abolished SCN (GranadosFuentes et al., 2004a). The rhythmic activity of Per1 was shown to be intrinsic to mitral and (possibly) tufted cells, suggesting that the main output neurons of the $\mathrm{OB}$ possess the internal clock (Granados-Fuentes et al., 2004b). Circadian expression of c-Fos, a marker of neuronal activity, was also induced in the $\mathrm{OB}$ layers and the piriform cortex (PC, part of the olfactory cortex) in response to odor, even with an abolished SCN (GranadosFuentes et al., 2006). Those data also showed that the OB, not the SCN, was responsible for maintaining the c-Fos rhythmicity in the PC, and olfactory responsivity would be highest at night (Granados-Fuentes et al., 2006, 2011). Olfactory discrimination itself was shown to be rhythmic, with highest sensitivity being at early night, and was dependent on the presence of Bmal1 and Per1/2 (Granados-Fuentes et al., 2006). Per1 expression in the $\mathrm{OB}$ also increases from day to night, corresponding to increasing discrimination (Abraham et al., 2005).

Unlike the retina, the known mechanisms that contribute to the autonomous clock in the $\mathrm{OB}$ are relatively scant. It can be speculated, however, that retaining the oscillation of odor functions such as discrimination, threshold perception, and odor-evoked behavior (e.g., foraging, predator avoidance) are important for increasing the chance of survival of vertebrates that depend on odor as much as humans depend on vision. This would especially make sense for nocturnal rodents, whose olfactory sensitivity would need to be highest during dusk or nighttime. Dopamine is known to impact olfactory discrimination (Tillerson et al., 2006; Escanilla et al., 2009). However, it is not known what impact dopamine may have on the circadian rhythms of the OB. Our group had previously found that OB dopamine demonstrates diurnal activity, with highest activity occurring when lights are on and lowest levels when lights are off (Corthell et al., 2013). This may suggest that either these dopamine neurons have an autonomous rhythm or that their rhythms are regulated by other neurons, possibly the M/TCs (Granados-Fuentes et al., 2004b). A neuropeptide called vasoactive intestinal polypeptide (VIP) may contribute to dopamine rhythms. VIP, acting through its receptor $\mathrm{VPAC}_{2}$, is crucial for the rhythmic expression of PER2 and odor detection (Miller et al., 2014). Because VIP itself is expressed in the GL and the EPL, and its receptor is expressed by M/TCs and ETCs (Miller et al., 2014; and our own unpublished findings), it may be possible that VIP directly or indirectly influences the rhythmicity of dopamine neurons and, perhaps, all other JGCs in the glomeruli.

Additionally, our group showed that melatonin receptors and another one of its biosynthesis enzymes, hydroxyindole-Omethyltransferase (HIOMT), is found in the OB (Corthell et al., 2014). The receptor and enzyme mRNAs fluctuate in a diurnal fashion, with HIOMT showing the lowest expression during lights-on and highest expression during lights-off (Corthell et al., 2014). We also showed that melatonin receptor activation impacts the biophysical activity of JGCs, including decreasing their outward $\mathrm{K}^{+}$current $\left(\mathrm{I}_{\mathrm{K}}\right)$ (Corthell et al., 2014), affecting those neurons' excitability. While it is not known if melatonin is produced in the $\mathrm{OB}$ endogenously, these results imply that melatonin and its receptors may contribute the autonomous clock of the OB. Furthermore, given that dopamine and melatonin provide inhibitory feedback to each other in the retina, they may display a similar activity in the $\mathrm{OB}$ (this rhythm is proposed in Figure 3B). These are some of the avenues we plan to further study to better identify the mechanisms of $\mathrm{OB}$ circadian rhythms. 

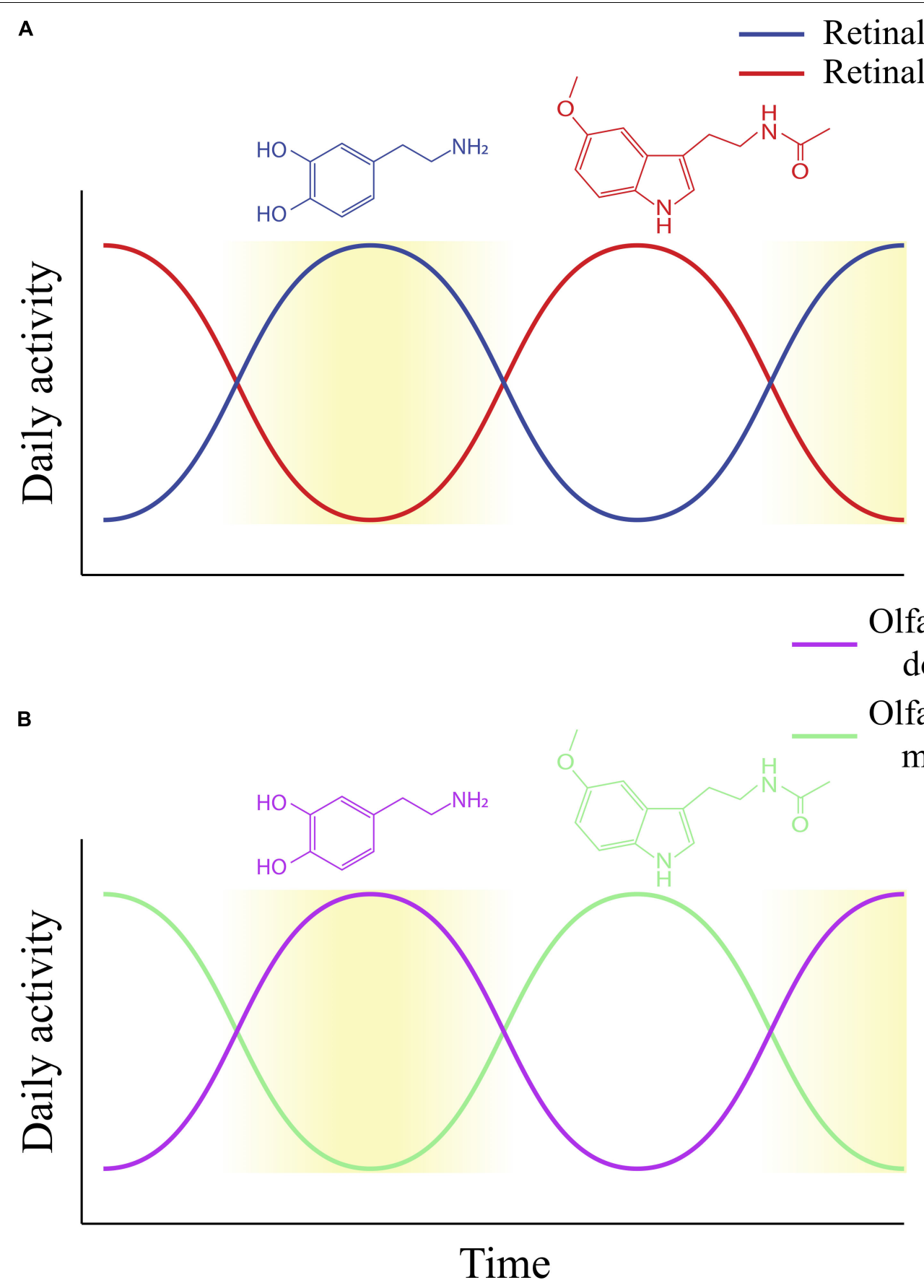

FIGURE 3 | The daily rhythms of dopamine and melatonin activity, as established within the retina (A) and proposed within the olfactory bulb (B). Increasing yellow gradient indicates an increase in the level of light to which the retina is exposed (A) or is an indicator of the time of day for the olfactory bulb (B). (A) Retinal dopamine synthesis and activity is highest during daytime, while retinal melatonin activity is highest during nighttime. This figure does not make the distinction between light-driven and circadian dopamine synthesis and release. While both would produce similar rhythms (dopamine is highest during the daytime or subjective day), dopamine release in constant darkness (circadian) would be much lower than light-stimulated dopamine release. (B) The proposed daily rhythm of dopamine in the olfactory bulb based on our prior study on dopamine content and release over $24 \mathrm{~h}$ in a12-h light/dark cycle. We found that olfactory bulb dopamine demonstrates diurnal activity, with highest activity occurring when lights are on and lowest levels when lights are off (Corthell et al., 2013). The proposed daily melatonin rhythm in the olfactory bulb is based on our prior determination of levels of mRNA for melatonin synthesizing enzymes in rats exposed to 12-h light/dark cycles. We found that HIOMT mRNA, for example, fluctuates in a diurnal fashion, with the lowest expression during lights-on and highest expression during lights-off (Corthell et al., 2014). Thus, this figure illustrates potential diurnal rhythms of olfactory bulb dopamine and melatonin, which peak in the daytime and nighttime, respectively. However, it has not been determined whether olfactory bulb dopamine and melatonin display circadian rhythms. 


\section{STIMULUS-DEPENDENT ACTIVATION}

\section{Light-Driven Activation and Synthesis of Retinal Dopamine}

It is universally accepted that retinal dopamine levels and activity increase with light (Figure 3A). This increase in dopamine allows the retina to transition from scotopic, rod-driven processing to photopic, cone-driven processing (Witkovsky, 2004; Roy and Field, 2019). Dopamine synthesis and activity spikes in response to light onset (Nir et al., 2000a). Neuronal activity in response to white light (Godley and Wurtman, 1988) also increases with the light intensity (Brainard and Morgan, 1987). An increase in light-driven phosphorylation of $\mathrm{TH}$ corresponds to the increase in dopamine synthesis (Iuvone, 1984). Light activity or activation of $\mathrm{D}_{1} \mathrm{R}$ increases phosphorylation of $\mathrm{TH}$ and also increases c-Fos labeling in the TH/dopaminergic neurons (Koistinaho and Sagar, 1995). The specific TH sites that are phosphorylated by light (as well as glutamate- and acetylcholine- mediated activation) are serine residues 19, 31, and 40 (Witkovsky et al., 2000). Increasing spiking activity also increases the phosphorylation of $\mathrm{TH}$ at these three sites, and vice versa (Witkovsky et al., 2004).

In bright light, activated ON-BCs excite retinal dopamine neurons. The "stratification rule" of the IPL dictates that ON-BCs would excite dopamine neurons in the ON sublamina of the IPL, which was confirmed to occur in stratum 3 of the IPL (Contini et al., 2010). However, evidence also exists that ON-BCs excite retinal dopamine neurons in the OFF sublamina (stratum 1) of the IPL, breaking this rule (Dumitrescu et al., 2009; Hoshi et al., 2009). It is possible that retinal dopamine neurons receive two excitatory inputs from the ON-BCs: via an en passant synapse in the OFF sublamina and through a classical synapse of the $\mathrm{ON}$ sublamina. Interestingly, the excitatory input from ON-BCs may not be needed to drive this phosphorylation/dopamine synthesis (Witkovsky et al., 2000). This result may suggest that other sources, including the input from ipRGCs (Zhang et al., 2008; Prigge et al., 2016), are also driving this activity.

However, despite a previous report (Doyle et al., 2002b), even further evidence shows that photoreceptors are necessary for dopamine synthesis and activity. Mice that carry a mutation that causes them to lose the outer segment of their photoreceptor (retinal dystrophy) with age show significantly lower levels of dopamine synthesis compared to wildtypes (Nir and Iuvone, 1994; Nir et al., 2000b). This effect is more pronounced in homozygotes (all photoreceptors degenerated) than heterozygotes (half photoreceptors present) (Nir et al., 2000b). Yet, a relatively high steady state level of dopamine, just not dopamine synthesis, is still retained in these retinas (Nir and Iuvone, 1994). It can also be considered that melatonin which is higher during the nighttime (Figure 3A) and has an antagonistic interplay with dopamine (Iuvone, 1986), but for which dopamine is also dependent upon to have functional circadian rhythms (Doyle et al., 2002a; Ribelayga et al., 2004; Bartell et al., 2007) - is present even in the absence of functional photoreceptors, but its rhythms are abolished (Tosini and Menaker, 1998). Activation driven by ipRGCs can be considered as an alternative pathway to rod and cone photoreceptors, but this is further complicated by new findings that argue that rod-activated BCs are the sole source of excitation for the retinal dopamine neurons (Munteanu et al., 2018; PérezFernández et al., 2019). Thus, further research is needed to fully understand all the light-driven activation pathways of retinal dopamine neurons.

Lastly, light influences the biophysical activity of dopaminergic neurons in different ways, providing insight that this neuronal population is not as homogenous as expected. Some retinal dopamine neurons produce a transient (brief, burst at the onset of the stimulus) response to light, others produce a sustained (similar spike frequency throughout the duration of the stimulus) response, while others produce no response to light at all (maintain their spiking frequency before and after the light stimulus) (Zhang et al., 2007, 2008). These findings and their implications are further discussed in section "The Spiking Profile of Retinal Dopamine Neurons."

\section{Stimulus-Evoked Synthesis of Dopamine in the Olfactory Bulb}

Deep to the $\mathrm{GCL}_{\mathrm{OB}}$ is the subependymal layer (Ennis et al., 2007, 2015). This layer receives a large number of adult-born GCs that migrate to the deeper layers of the $\mathrm{OB}\left(\mathrm{GCL}_{\mathrm{OB}}, \mathrm{IPL}_{\mathrm{OB}}\right.$, and MCL), dopamine neurons, and other JGCs that mostly migrate to the GL (Luskin, 1993; Ennis et al., 2007, 2015). The migration of these progenitor neurons is very much an active process, as some 10,000 new interneurons enter the mouse OB every day (Nagayama et al., 2014). Adult-born progenitor neurons migrate from the SVZ to the OB via the rostral migratory stream (RMS). Once migrated to the $\mathrm{OB}$, if the immature neurons express the transcription factors Pax6 and Olig2 (Hack et al., 2005) and are able to receive excitatory synaptic input, they can differentiate into the dopaminergic phenotype.

There is a wealth of findings that show that when an animal's nasal cavity is obstructed from receiving odors (naris occlusion), which leads to a decrease in OSN stimulation of the ipsilateral OB hemisphere, the OB dopamine neurons decrease their expression of TH (Baker et al., 1983; Baker, 1990; Wilson and Wood, 1992; Wilson and Sullivan, 1995), $\mathrm{D}_{2}$ Rs increase their density in the ONL and GL (Guthrie et al., 1991), and the M/TCs become more responsive to odor stimuli (Guthrie et al., 1990). The decrease in $\mathrm{TH}$ expression was originally thought to not be indicative of dopaminergic cell death, because L-amino acid decarboxylase (the enzyme that converts L-DOPA to dopamine) was still expressed during naris occlusion (Baker et al., 1984), suggesting only a decrease in dopamine synthesis. However, more recent studies show that dopamine density decreases following prolonged (1-4 weeks) naris occlusion (Sawada et al., 2011; Grier et al., 2016). This loss is likely driven by microglia, which became activated during naris occlusion and appeared to engulf dopaminergic synapses (Grier et al., 2016). Subsequent naris reopening was shown to increase the number of newborn $\mathrm{OB}$ dopamine neurons (Sawada et al., 2011). Thus, the survival of OB dopamine neurons depends on OSN input (Sawada et al., 2011). TH expression also appears to be governed by OSN 
input, likely through the activation of the NMDA glutamate receptors (Puche and Shipley, 1999) and the L-type $\mathrm{Ca}^{2+}$ channel (Cigola et al., 1998).

It was originally thought that $\mathrm{OB}$ dopamine neurons only express TH once they reach the GL (McLean and Shipley, 1988), where they form excitatory synapses with OSNs' terminals and the apical dendrites of M/TCs. Both OSNs (Berkowicz et al., 1994; Ennis et al., 1996) and M/TCs (Trombley and Westbrook, 1990) release glutamate at these synapses. However, subsequent findings indicated that $\mathrm{TH}$ expression is also present in layers deep to the GL, including the EPL, MCL, and GCL (Baker et al., 2001; Pignatelli et al., 2009; Kosaka et al., 2019; Korshunov et al., 2020). There is no conclusive finding to explain why TH expression can occur deep to the GL, but Pignatelli et al. (2009) had found that even $\sim 75 \%$ of the deep (in the EPL) $\mathrm{TH}$ green fluorescent protein (GFP) neurons are capable of responding to OSN stimulation. Other possible reasons may include that these neurons also receive glutamatergic input from the lateral dendrites of M/TCs. Or, they may be in proximity to glutamate spillover, also from the M/TCs. In all cases, there can be several pathways in which glutamate can activate the NMDA receptors and eventually the L-type $\mathrm{Ca}^{2+}$ channels, leading to increased TH expression. All possibilities seem likely, because even the deep TH-GFP neurons (whether in the EPL or the MCL) show an excitatory response to glutamate application (Pignatelli et al., 2009).

This population of OB dopamine neurons deep to the GL was classified as "immature" by some investigators (Pignatelli et al., 2009). Pignatelli et al. (2009) found that deep dopamine neurons in the EPL and MCL possess a larger intracellular $\mathrm{Cl}^{-}$ concentration than those within the GL. A high intracellular $\mathrm{Cl}^{-}$ concentration is a hallmark of immature neurons (Ben-Ari et al., 2007), making this classification enticing. However, it is unclear whether their high $\mathrm{Cl}^{-}$concentration is a function of immaturity or is a marker of a particular type of $\mathrm{OB}$ dopamine neuron. Further research is needed to answer the question as to whether these deep dopamine neurons are immature.

\section{BIOPHYSICAL PROPERTIES}

\section{The Spiking Profile of Retinal Dopamine Neurons}

The biophysical properties of dopamine (and other) neurons include action potential spiking, activation of ionic currents, and signal facilitation. These properties show how dopamine neurons behave spontaneously and how they respond to stimuli (whether natural or artificial). These intrinsic biophysical activities can provide insight into how retinal and $\mathrm{OB}$ neurons influence their neuronal circuitry. In the absence of synaptic input, cultured retinal dopamine neurons showed spontaneous spiking activity within the $\theta$-frequency (less than $\sim 10 \mathrm{~Hz}$ or spikes per second) (Gustincich et al., 1997; Feigenspan et al., 1998). This spiking frequency increases with additional depolarizing current and with kainate (glutamate receptor agonist) application, and it is conversely blocked by GABA and $\mathrm{D}_{2} \mathrm{R}$ activation (Gustincich et al., 1997; Puopolo et al., 2001). This action potential spiking in cultured retinal dopamine neurons appears to be required for the vesicular release of dopamine (Puopolo et al., 2001). Thus, dopamine activity and release may increase above background/spontaneous activity in the daytime through increased ON-BC (and from other sources) excitation in the daytime, and decrease through increased inhibitory input from ACs (which would likely be stimulated by the OFF-BCs) during the nighttime (Gustincich et al., 1997; Puopolo et al., 2001; Zhang et al., 2007). Indeed, Zhang et al. (2007) confirmed that GABAergic and glycinergic antagonists increased spontaneous spiking and more instances of bursting from dopamine neurons in the dark. These effects of GABA are likely most prevalent during darkness in the nighttime (as opposed to darkness stimuli in the daytime), because melatonin may act through $\mathrm{GABA}_{\mathrm{A}} \mathrm{R}$ to inhibit dopamine neurons (Boatright et al., 1994). Therefore, these neurons display spontaneous spiking that is synaptically regulated, with increased excitatory drive in the daytime and increased inhibition in the night.

As mentioned in section "Light-Driven Activation and Synthesis of Retinal Dopamine," retinal dopamine neurons display heterogenous spiking activities in response to light. Recordings from mouse dopaminergic neurons in retinal slices show that, surprisingly, not all neurons respond to light (Zhang et al., 2007). Only $60 \%$ of the recorded neurons responded (increase in spike frequency) to light, while the rest did not respond (but they still showed spontaneous activity) (Zhang et al., 2007). The dopamine neurons that did respond to light were further differentiated by their specific activities: a majority produced a transient response (rapid bursting of action potentials at the onset of the light stimulus, followed by a decrease in spiking frequency), and the minority displayed a sustained response (action potential frequency increased to light onset, and maintained this frequency throughout the duration of the stimulus) (Zhang et al., 2007). These "transient" and "sustained" groups of dopamine neurons were most responsive to wavelengths of green, then blue, and least responsive to red light (Zhang et al., 2007). These spiking properties are modulated by synaptic excitation and inhibition (Zhang et al., 2007), so these groups of dopamine neurons likely receive different synaptic input in order to generate this difference in spiking properties. While the transient group is likely driven by ON-BCs, the sustained group was determined to be driven by ipRGCs (Zhang et al., 2007, 2008).

Because the melanopsin-expressing ipRGCs are considered to be the "third" photoreceptor of the retina (Berson et al., 2002; Hattar et al., 2002), and because they provide glutamatergic input to retinal dopamine neurons (Zhang et al., 2012; Prigge et al., 2016; Liu et al., 2017), it is likely that they are responsible for driving the sustained light response in dopamine neurons that is independent of the transient light response driven by cone ON-BCs. By blocking out the ON-BC input via L-AP4, an agonist for the metabotropic glutamate receptor mGluR6, which blocks transmission from photoreceptors onto ON-BCs, the sustained group of dopamine neurons was effectively isolated (Zhang et al., 2008). These neurons responded most to blue wavelength ( $\sim 478 \mathrm{~nm})$, which is the wavelength to which the melanopsin in ipRGCs is most responsive (Lucas et al., 2001; 
Hattar et al., 2003; Zhang et al., 2008). Conversely, transient neurons responded more to the $500 \mathrm{~nm}$ wavelength (Zhang et al., 2008), which is the wavelength to which the opsin photopigments of rods and middle (green) wavelength cone photoreceptors are most responsive (Jacobs et al., 1991). This sustained response was preserved in retinas with degenerated rod and cone photoreceptors (Zhang et al., 2008). c-Fos labeling was also found in dopaminergic neurons and ipRGCs following light stimulation (while simultaneously blocking the cone and rod photoreceptor pathways with L-AP4) (Zhang et al., 2008). Thus, the group of dopamine neurons that respond to light in a sustained manner depend on light signaling from ipRGCs (Zhang et al., 2008). Subsequent studies have also established a glutamatergic, presynaptic input from ipRGCs to dopaminergic neurons (Zhang et al., 2012; Prigge et al., 2016; Liu et al., 2017). Lastly, without functional melanopsin in ipRGCs, the light-evoked increase in TH mRNA, which is normally present in wildtype retinas, is absent in these modified retinas (Dkhissi-Benyahya et al., 2013).

\section{The Spiking Profile of Olfactory Bulb Dopamine Neurons}

Many key findings that have provided important insight into the biophysical properties of $\mathrm{OB}$ dopamine neurons have come with the advent of transgenic mouse models with neurons that express GFP linked to TH, making these fluorescent dopamine neurons an easy target for electrophysiology recordings. The most distinctive feature of these $\mathrm{OB}$ dopamine neurons was their spontaneous activity (Pignatelli et al., 2005, 2009, 2013; Puopolo et al., 2005). Like in the retina, OB dopamine neurons' spiking was within the $\theta$-frequency $(\sim 8 \mathrm{~Hz})$ in OB slices (Pignatelli et al., 2005). Also like in the retina (Puopolo et al., 2001), action potentials likely increase vesicular dopamine release (Borisovska et al., 2013). Interestingly, some of the aforementioned deep dopamine neurons also displayed this spontaneous spiking (specifically those recorded from the EPL), while other deeper neurons (recorded in the MCL) did not (Pignatelli et al., 2009). When these dopamine neurons were dissociated, their spiking increased to slightly above the $\theta$-frequency $(\sim 13 \mathrm{~Hz})$ than what was seen in slice (Pignatelli et al., 2005), indicating that these neurons likely receive some inhibition in slice. This spontaneous activity was found to be driven by the TTX-sensitive persistent $\mathrm{I}_{\mathrm{Na}}$, the T-type $\mathrm{Ca}^{2+}$ current $\left(\mathrm{I}_{\mathrm{Ca}}\right)$, and the hyperpolarization-activated cation h-current $\left(\mathrm{I}_{\mathrm{H}}\right)$ (Pignatelli et al., 2005, 2013; Puopolo et al., 2005).

We recently published findings on the biophysical properties of rat $\mathrm{OB}$ dopamine neurons, and described how these properties may distinguish different groups of dopamine neurons (as was discussed in section "Olfactory Bulb Dopamine Neurons") (Korshunov et al., 2020). Similar to previous work in mice, we used a transgenic rat model (Iacovitti et al., 2014) with dopamine neurons that expressed a fluorescent protein to easily target cells. Recording from rat OB TH-GFP neurons also provided the opportunity to identify potential species differences between rats and mice. For example, none of the neurons from which we recorded displayed spontaneous spiking, only showing synaptically driven potentiation; this indicates a potential functional difference in the background activity between rat and mouse $\mathrm{OB}$ dopamine neurons, suggesting a possible functional and species difference (Pignatelli et al., 2005; Puopolo et al., 2005; Korshunov et al., 2020). We also found that, when these neurons were grouped based on their neuronal areas (in which we classified them as either "Large" or "Small" dopamine neurons), the Large dopamine neurons produced more action potentials in response to weak current stimuli, while the Small neurons only produced a more phasic/single spiking response to these stimuli (Korshunov et al., 2020). When stimulated with stronger current stimuli, the Large and Small neurons both produced the same phasic/single spiking response (Korshunov et al., 2020). This difference in responses was likely due to inactivation properties of the voltage-gated $\mathrm{Na}^{+}\left(\mathrm{Na}_{\mathrm{V}}\right)$ channels. In Small neurons, $\mathrm{Na} V$ channels were significantly more inactivated than those of Large neurons, especially at slightly depolarized membrane potentials ( -70 and $-60 \mathrm{mV}$ ), which likely drives the increased responsiveness of Large but not Small neurons to weak stimuli (Korshunov et al., 2020). Furthermore, Small neurons displayed a significantly stronger $\mathrm{I}_{\mathrm{H}}$ than Large neurons, which could further inactivate their $\mathrm{Na}_{V}$ channels by increasing their resting membrane potentials (Korshunov et al., 2020).

These putative "Large" dopamine neurons are likely ones that possess an axon, while the "Small" neurons do not (Chand et al., 2015; Galliano et al., 2018). These axonic, Large dopamine neurons are overall more excitable than their anaxonic counterparts: they spike at more hyperpolarized membrane potentials, have faster spike onset, and spike at a higher frequency than the Small neurons in OB cultures (Chand et al., 2015) and slices (Galliano et al., 2018). Thus, the presence of an axon can be indicative of the excitability profile of the Large $\mathrm{OB}$ dopamine neurons (Chand et al., 2015; Galliano et al., 2018). These excitability profiles can contribute to the functional hypothesis of $\mathrm{OB}$ dopamine serving as a high-pass filter. We discuss this further in the "Neuromodulation" section "Dopamine's Neuromodulation of the Olfactory Bulb."

\section{NEUROMODULATION}

\section{Dopamine's Neuromodulation of the Retina}

The daytime increase in dopamine allows the retina to adapt to light by increasing visual acuity and contrast sensitivity through various modulatory mechanisms (Witkovsky, 2004; Roy and Field, 2019). Dopamine modulates virtually every neuron in the retina, ultimately modulating the activity and receptive fields of RGCs. While many of these effects occur with dopamine acting directly on the synapses of retinal neurons, many of these changes also occur by modulating the gap junction proteins in between retinal neurons (Figure 1). Gap junctions are composed of homomeric or heteromeric connexin proteins that couple cells together, allowing for quick, electrical impulses to travel from one cell to another without a conventional chemical synapse. Different modulatory mechanisms can phosphorylate or dephosphorylate gap junctions, causing them to either close (uncouple) or open (couple) their connexin protein channels. When two cells of the same type are connected by a gap 
junction (e.g., rod-rod), they form a homotypic connection, while a heterotypic connection forms when gap junctions connect two different cells (e.g., BC-AC). The various neuromodulatory mechanisms of dopamine, beginning with photoreceptors, are summarized below. These effects (and the species in which they were analyzed) are also summarized in Table $\mathbf{1}$.

Photoreceptors must regulate their gap junctions' coupling in order to adjust to the environmental lighting. During the night, photoreceptors are coupled, which helps increase the signal-to-noise ratio in low lighting, while they are uncoupled during the day (Tessier-Lavigne and Attwell, 1988; DeVries et al., 2002; Jin et al., 2015). The main connexin gap junctions that are present in mammalian and non-mammalian vertebrate photoreceptors are connexin 36 (Cx36) (O'Brien et al., 2012; Li et al., 2014). Dopamine is one of the main modulators of photoreceptor coupling. In the daytime, when its levels are high, dopamine decreases coupling between rods-cones, conescones, and rods-rods by activating the $\mathrm{D}_{2}$-like/ $\mathrm{D}_{4}$ Rs present on these photoreceptors (Ribelayga et al., 2008; Li et al., 2013; Jin et al., 2015). Activation of $\mathrm{D}_{2}$-like/ $\mathrm{D}_{4}$ Rs decreases the adenylyl cyclase/cAMP activity (Nir et al., 2002; Jackson et al., 2009, 2011; Hwang et al., 2013), which eventually dephosphorylates the Cx36 and uncouples it between the photoreceptors (Li et al., 2013). Interestingly, this mechanism also occurs in a circadian fashion, during the subjective day but in the absence of light (Ribelayga et al., 2008). This occurs because, during the subjective day, the antagonistic actions of retinal melatonin are low, leading to an increase in dopamine release (Ribelayga et al., 2008). The $\mathrm{D}_{2}$ like receptors have a higher affinity for dopamine than $D_{1} R s$, and because dopamine is released in a circadian fashion without additional release in response to light stimuli, these relatively low levels of dopamine are enough to uncouple photoreceptors via $\mathrm{D}_{2}$-like receptors in photoreceptors (Ribelayga and Mangel, 2003; Ribelayga et al., 2008). By uncoupling photoreceptors, dopamine also helps increase the contrast sensitivity (the ability to contrast between variations of light intensities) (Jackson et al., 2012). Besides gap junctions, dopamine directly influences the excitability of rods by inhibiting their $\mathrm{Na}^{+} / \mathrm{K}^{+}$ATPase activity via the $\mathrm{D}_{2}$-like/ $\mathrm{D}_{4} \mathrm{Rs}$ (Shulman and Fox, 1996). Dopamine also inhibits the $\mathrm{I}_{\mathrm{H}}$ in rods through a $\mathrm{D}_{2}$-like $/ \mathrm{D}_{4} \mathrm{R}$ activation in amphibian (Akopian and Witkovsky, 1996) and human retinas (Kawai et al., 2011). While it can be assumed that a decrease in $\mathrm{I}_{\mathrm{H}}$ would decrease the excitability of rods (Kawai et al., 2011), further details are needed.

In the INL, the inhibitory HCs are coupled during the night and uncoupled during the day by dopamine (Roy and Field, 2019). Specifically, HCs are uncoupled by the activation of $D_{1}$ Rs (Harsanyi and Mangel, 1992; Wang et al., 1997; Ribelayga and Mangel, 2003; Zhang et al., 2011). Unlike the circadian-driven activation of the $\mathrm{D}_{2}$-like/ $\mathrm{D}_{4} \mathrm{Rs}$ that uncouples photoreceptors, light is needed to release higher levels of dopamine to uncouple $\mathrm{HCs}$ by activating the low-affinity $\mathrm{D}_{1}$ Rs (Ribelayga and Mangel, 2003). Conversely, the circadian-driven dopamine release at night (though its basal levels are still lower than daytime)

TABLE 1 | Neuromodulatory effects of dopamine receptors on retinal neurons.

\begin{tabular}{|c|c|c|c|}
\hline Cell type & $\mathbf{D}_{1}$ & $D_{2} / D_{2}$-like receptor & $\mathbf{D}_{4}$ \\
\hline Photoreceptors & - & $\begin{array}{l}\text { - Decreases rod-rod, rod-cone, } \\
\text { cone-cone coupling (mice) } \\
\text { - Decreases the } \mathrm{I}_{H} \text { in rods (amphibians } \\
\text { and humans) } \\
\text { - Decreases melatonin production } \\
\text { (amphibians) } \\
\text { - Inhibits the } \mathrm{Na}^{+} / \mathrm{K}^{+} \text {ATPase } \\
\text { activity (rats) }\end{array}$ & $\begin{array}{l}\text { - Inhibits melatonin synthesis (rat) } \\
\text { - Decreases cAMP cascade (mice) } \\
\text { - Decreases rod-cone coupling (mice } \\
\text { and fish) }\end{array}$ \\
\hline $\mathrm{HCs}$ & $\begin{array}{l}\text { - Uncouples gap junctions (fish } \\
\text { and primates) }\end{array}$ & $\begin{array}{l}\text { - Indirectly couples gap junctions } \\
\text { through the autoreceptor inhibition of } \\
\text { dopamine release (fish) }\end{array}$ & - \\
\hline \multirow[t]{2}{*}{$\mathrm{BCs}$} & $\begin{array}{l}\text { - Decreases } \mathrm{Na}_{v} \text { activity of } \\
\text { ON-BCs (mice) }\end{array}$ & - & - \\
\hline & $\begin{array}{l}\text { - Helps decrease the spatial inhibition } \\
\text { of rod- and OFF-BCs by inhibiting ACs } \\
\text { (mice) }\end{array}$ & & \\
\hline ACs & - Uncouples gap junctions (rabbits) & - & - \\
\hline RGCs & $\begin{array}{l}\text { - Couples homotypic (RGC-RGC) and } \\
\text { heterotypic (RGC-AC) gap junctions } \\
\text { (mice and rabbits) } \\
\text { - Decreases } I_{\mathrm{Na}} \text { amplitude (fish and } \\
\text { rats), and decreases action potential } \\
\text { spiking (rats) }\end{array}$ & $\begin{array}{l}\text { - Uncouples gap junctions (rabbits) } \\
\text { - Decreases } I_{K} \text { and increases } I_{N a} \text { (rats) }\end{array}$ & $\begin{array}{l}\text { - Modulates NPAS2 and adenylyl } \\
\text { cyclase } 1 \text { activity, leading to increased } \\
\text { contrast sensitivity (Not clear if } D_{4} \text { Rs } \\
\text { expressed by RGCs) (mice) }\end{array}$ \\
\hline ipRGCs & $\begin{array}{l}\text { - Attenuates melanopsin-based } \\
\text { photocurrent (rats) }\end{array}$ & $\begin{array}{l}\text { - Regulates the expression of } \\
\text { melanopsin mRNA (rats) }\end{array}$ & - \\
\hline
\end{tabular}

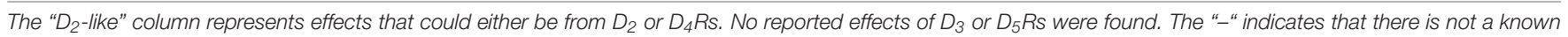

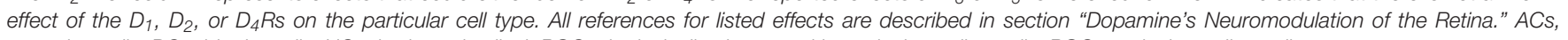
amacrine cells; BCs, bipolar cells; HCs, horizontal cells; ipRGCs, intrinsically photosensitive retinal ganglion cells; RGCs, retinal ganglion cells. 
may still partially uncouple the HCs, as there is evidence that shows that the $\mathrm{D}_{1} \mathrm{R}$ antagonist ( $\left.\mathrm{SCH}-23390\right)$ was capable of increasing the receptive field of $\mathrm{HCs}$ in the absence of light (Zhang et al., 2011). As HCs provide an antagonistic receptive field to the surrounding photoreceptors and the excitatory BCs (Roy and Field, 2019), daytime dopamine activity would decrease this inhibitory receptive field by uncoupling HCs, which could increase visual acuity (how accurately an object can be visually discerned) (Jackson et al., 2012). On the other end, activation of the $\mathrm{D}_{2}$ Rs indirectly increases $\mathrm{HC}$ coupling, because $\mathrm{D}_{2}$ Rs are expressed as autoreceptors on the dopaminergic neurons (at least in fish retinas) (Harsanyi and Mangel, 1992; Wang et al., 1997). Activation of the $\mathrm{D}_{2}$ autoreceptors would decrease dopamine release, thus, maintaining/increasing coupling of HCs (Harsanyi and Mangel, 1992; Wang et al., 1997).

Retinal dopamine affects the signal input onto RGCs by directly and indirectly modulating the activity of various BCs. $D_{1} R$ activation decreases the excitability of ON-BCs by decreasing their $\mathrm{Na}_{\mathrm{V}}$ conductance when these neurons are activated by a light stimulus during the night (Smith et al., 2015). Dopamine is effective at decreasing ON-BC excitation when these neurons are presented with the light stimulus during night but not during day, likely in order to decrease ON-BC saturation in response to light (Smith et al., 2015). $\mathrm{D}_{1} \mathrm{R}$ activation can also decrease the light-evoked inhibition of rod BCs by presynaptically inhibiting the inhibitory activity of ACs (Flood et al., 2018). Likewise, cone OFF-BCs become inhibited by GABA and glycine released from ACs in lighted conditions (Mazade and Eggers, 2016). However, long light stimuli eventually decrease the spatial inhibition of ACs onto OFF-BCs, allowing them to adapt to the lighting condition (Mazade and Eggers, 2016). Part of this light-adapted decrease in inhibition is due to the activation of $\mathrm{D}_{1} \mathrm{Rs}$, which presynaptically decrease the release of glycine from ACs (Mazade et al., 2019). Beyond $D_{1} R$ activity, other mechanisms likely contribute to the light adaptation of BCs.

Dopamine affects the coupling between the AII class of ACs, which may increase spatial acuity in bright lighting (Demb and Singer, 2012; Roy and Field, 2019). In moderate lighting (e.g., moonlight), the AII ACs receive excitatory input from rod BCs and transfer this signal via homotypic coupling between other AIIs toward the cone-driven ON-BCs via heterotypic coupling, thus, integrating the rod pathway into the cone pathway (Demb and Singer, 2012). AII ACs express $D_{1}$ Rs (Nguyen-Legros et al., 1997; but see also: Veruki and Wässle, 1996). $D_{1} R$ activation decreases homotypic coupling between the AII ACs (Hampson et al., 1992; Kothmann et al., 2009). At photopic light, this reduced coupling may increase acuity by decreasing the receptive fields of inner retinal neurons (BCs, ACs, and RGCs) that receive coupled excitatory or synaptic inhibitory (glycinergic) input from the AII ACs (Demb and Singer, 2012). Dopaminergic retinal neurons further affect the AII ACs by releasing GABA onto the AC somas, likely under the same lighting conditions at which dopamine is released (Contini and Raviola, 2003). This GABAergic inhibition from dopamine neurons also affects the ON-BCs (which provide the excitatory input onto the phasic group of dopamine neurons - Zhang et al., 2007) in the ON (stratum 3) portion of the IPL (Contini et al., 2010).
These presynaptic inhibitory mechanisms of AIIs and ON-BCs are proposed to decrease noise from the rods during photic illumination (Contini et al., 2010).

Lastly, dopamine has numerous effects on the RGCs and the ipRGCs, which affects their coupling and biophysical activity. Light and $\mathrm{D}_{1} \mathrm{R}$ activation increases the homotypic coupling between the $\alpha$ group of OFF-RGCs and the heterotypic coupling between $\alpha$ OFF-RGCs and ACs (Hu et al., 2010). Conversely, $\mathrm{D}_{2} \mathrm{R}$ activation uncoupled the $\alpha$ OFF-RGCs (Mills et al., 2007). The implications of these effects are not clear (Roy and Field, 2019), but increased heterotypic and homotypic coupling does increase synchronous activity of the $\alpha$ OFF-RGCs (Hu et al., 2010), which would impact the visual signal transmission being sent via the optic nerve. Much is also understood about how dopamine affects the biophysical properties of RGCs and ipRGCs. In RGCs, $\mathrm{D}_{1} \mathrm{R}$ activation decreases the $\mathrm{I}_{\mathrm{Na}}$ amplitude, modulates these neurons' $\mathrm{I}_{\mathrm{H}}$, and overall decreases their spiking (Hayashida and Ishida, 2004; Chen and Yang, 2007; Hayashida et al., 2009). Conversely, $\mathrm{D}_{2} \mathrm{R}$ activation decreases the $\mathrm{I}_{\mathrm{K}}$ and increases the $\mathrm{I}_{\mathrm{Na}}$ in these neurons, likely increasing overall excitability (Yin et al., 2020). Likewise, dopamine decreases the photocurrent of the ipRGCs via $D_{1} R$, thus reducing the light-driven spiking, but also decreases the light-independent background spiking (Van Hook et al., 2012).

These results paint a complex, yet a profound picture of how dopamine can mediate the transition from retinal daytime to nighttime activity.

\section{Dopamine's Neuromodulation of the Olfactory Bulb}

Dopamine acts on the first synaptic contact in the glomeruli of the $\mathrm{OB}$, where it can modify the transmission of the odor signal (Figure 2). The neuromodulatory effects of dopamine are mediated through the $\mathrm{D}_{1}$ and $\mathrm{D}_{2} \mathrm{Rs}$, which are summarized (along with the specific species) in Table 2. To the best of our knowledge, no expression nor activity of $\mathrm{D}_{3}, \mathrm{D}_{4}$, or $\mathrm{D}_{5} \mathrm{Rs}$ have been found in the $\mathrm{OB}$. The activity of $\mathrm{OB} \mathrm{D}_{2}$ Rs has been implicated in the modulation of odor discrimination (the ability to differentiate between two different odors) (Tillerson et al., 2006; Taylor et al., 2009), odor detection (Doty and Risser, 1989), and neonatal odor preference training (Coopersmith et al., 1991). During naris occlusion, which causes $\mathrm{TH}$ and dopamine to decrease, the M/TCs become more responsive to odor (Guthrie et al., 1990; Wilson and Sullivan, 1995) and OSN stimulation (Wilson and Wood, 1992), suggesting a decrease in odor discrimination. This effect was mimicked with application of the $\mathrm{D}_{2} \mathrm{R}$ antagonist spiperone in non-occluded OBs (Wilson and Sullivan, 1995). In another study, genetically modified mice lacking the $\mathrm{D}_{2} \mathrm{R}$ investigated novel odors significantly less than their wildtype counterparts, also indicating a decrease in discrimination (Tillerson et al., 2006). Additionally, the $\mathrm{D}_{2} \mathrm{R}$ agonist quinpirole decreased odor detection and discrimination in a dose-dependent manner (Doty and Risser, 1989; Escanilla et al., 2009). These last results may imply that activating $\mathrm{D}_{2} \mathrm{Rs}$ at high/saturating levels by agonists would decrease signal transmission from OSNs onto JGCs and/or M/TCs, thus 
TABLE 2 | Neuromodulatory effects of dopamine receptors on olfactory bulb neurons and astrocytes.

\begin{tabular}{|c|c|c|}
\hline Cell type & $\mathbf{D}_{1} \mathbf{R}$ & $\mathbf{D}_{2} \mathbf{R}$ \\
\hline OSNs & - & - Inhibits glutamate release (turtles, mice, and rats) \\
\hline PGCs & - & - May act as an autoreceptor \\
\hline ETCs & - Augments the $\mathrm{I}_{H}$ response following hyperpolarization (mice) & - \\
\hline SACs & - & - May act as an autoreceptor \\
\hline \multirow[t]{2}{*}{ M/TCs } & $\begin{array}{l}\text { - Indirectly inhibits M/TCs by increasing feedforward inhibition from } \\
\text { GCs (rats) }\end{array}$ & $\begin{array}{l}\text { - Enhances } \mathrm{GABA} / \mathrm{Cl}^{-} \text {current (rats) } \\
\text { - Inhibits glutamate release from apical dendrites (rats) } \\
\text { - Directly hyperpolarizes mitral cells (fish) }\end{array}$ \\
\hline & & - Decreases mitral cell spontaneous spiking (frogs) \\
\hline GCs & - Reduces $\mathrm{GABA}_{A} / \mathrm{Cl}^{-}$currents (rats) & - Indirectly reduces excitation of these neurons by inhibiting the M/TCs (frogs) \\
\hline Astrocytes & - Increases cytoplasmic $\mathrm{Ca}^{2+}$ (mice) & - Increases cytoplasmic $\mathrm{Ca}^{2+}$ (mice) \\
\hline
\end{tabular}

No reported effects from $D_{3}-D_{5} R s$ were found. The symbol "- "indicates that there is no known effect of the $D_{1}$ or $D_{2}$ receptor on the particular cell type. All references for listed effects are described in section "Dopamine's Neuromodulation of the Olfactory Bulb." ETCs, external tufted cells; GCs, granule cells; M/TCs, mitral/tufted cells; OSNs, olfactory sensory neurons; PGCs, periglomerular cells; SACs, short-axon cells.

decreasing odor discrimination due to a high detection threshold. Alternatively, inactivation of $\mathrm{D}_{2} \mathrm{Rs}$ by antagonists may decrease lateral glomerular inhibition, causing for more noise to be transmitted, and thus, for odor discrimination to also decrease due to a low signal-to-noise ratio. Therefore, to maintain proper levels of odor discrimination, certain glomeruli would need to be inactivated by dopamine while others would need to transmit the signal.

Each of the couple of thousand of $\mathrm{OB}$ glomeruli receives a unique odor signal - that pass from OSNs to M/TCs, while also being modulated by the JGCs - which allows the OB to code for specific odors (Kratskin and Belluzzi, 2003). Once activated, dopamine is released from JGCs and binds $\mathrm{D}_{2} \mathrm{Rs}$ (as well as its $\mathrm{GABA}$ binding the metabotropic $\mathrm{GABA}_{\mathrm{B}}$ receptor) on OSN terminals (Nickell et al., 1994; Hsia et al., 1999; AroniadouAnderjaska et al., 2000; Berkowicz and Trombley, 2000; Ennis et al., 2001; Liu et al., 2013; Vaaga et al., 2017) and the apical dendrites of M/TCs (Davila et al., 2003), causing a decrease in the presynaptic release of glutamate. Thus, $\mathrm{D}_{2} \mathrm{R}$ activation leads to an attenuation of postsynaptic excitation. This "inhibition of excitation" is likely caused by the $D_{2} R$ activating the $G_{\beta \gamma}$ protein, which inhibits the $\mathrm{N}$-type $\mathrm{Ca}^{2+}$ channels (Meir et al., 2000; Davila et al., 2003; Bettler et al., 2004). The N-type $\mathrm{Ca}^{2+}$ channels are involved in the vesicular release cascade (Miller, 1987; Weber et al., 2010), which may gate glutamate release from the OSN and M/TCs (Isaacson and Strowbridge, 1998). Additionally, $\mathrm{D}_{2} \mathrm{Rs}$ increase the $\mathrm{GABA} / \mathrm{Cl}^{-}$currents in $\mathrm{M} / \mathrm{TC}$ (Brünig et al., 1999), providing further inhibition to odor signal transmission. These inhibitory mechanisms may also occur via interglomerular dopamine and GABA release.

The activity of $\mathrm{OB} \mathrm{D}_{2} \mathrm{R}$ was hypothesized to be a part of the high-pass filter function of dopamine neurons (Ennis et al., 2001; Korshunov et al., 2017, 2020). That is, these inhibitory/GABAergic dopamine neurons inhibit (through the metabotropic $\mathrm{D}_{2} / \mathrm{GABA}_{\mathrm{B}} \mathrm{R}$ or ionotropic $\mathrm{GABA}_{\mathrm{A}} \mathrm{R}$ ) or "gate out" the weak, background odor stimulus (e.g., odor of rat bedding), but not the strong, prominent odor stimulus (e.g., predator's urine), which is passed along to the M/TCs and to further brain regions. Our findings that a subset of $\mathrm{OB}$ dopamine neurons more actively spike in response to weak but not strong current stimuli (Korshunov et al., 2020) suggest that these neurons are more likely to inhibit the weak odors but be unresponsive to strong odors. Additionally, $\mathrm{D}_{2} \mathrm{R}$ activation hyperpolarized the mitral cells in the fish $\mathrm{OB}$ and made them less responsive to weak stimuli, while also making them more responsive to strong stimuli (Bundschuh et al., 2012). In general, dopamine application produces reduced responses of M/TCs in several species (Nowycky et al., 1983; Duchamp-Viret et al., 1997; Berkowicz and Trombley, 2000; Davison et al., 2004), and naris occlusion (Guthrie et al., 1990, 1991; Wilson and Sullivan, 1995) or the absence of $\mathrm{D}_{2}$ Rs (Tillerson et al., 2006) produce the complete opposite effects. These mechanisms would conceivably increase odor discrimination and odor detection (Doty and Risser, 1989).

There is also some controversy about the effectiveness of $\mathrm{D}_{2}$ Rs in presynaptic inhibition (McGann, 2013). While there is a clear effect of exogenous dopamine $\mathrm{D}_{2} \mathrm{R}$ agonists, the role of endogenously released dopamine on presynaptic inhibition has been difficult to establish (McGann, 2013). Maher and Westbrook (2008) perhaps came closest to studying endogenous dopamine activity in mammalian $\mathrm{OB}$ by applying cocaine (dopamine reuptake blocker), which reduced postsynaptic currents from OSNs. This effect that was reversed with the application of the $\mathrm{D}_{2} \mathrm{R}$ antagonist sulpiride (Maher and Westbrook, 2008). However, they were unable to observe the same decrease in OSN postsynaptic excitation when stimulating dopamine neurons directly (Maher and Westbrook, 2008). The effects of sulpiride by itself (without exogenous dopamine or $\mathrm{D}_{2} \mathrm{R}$ agonists) did not reverse the decrease of postsynaptic OSN excitation, suggesting that tonic dopamine release may be low (McGann, 2013). Conversely, GABA may be more relevant in this presynaptic inhibitory role, because activation of the $\mathrm{GABA}_{\mathrm{B}} \mathrm{R}$ (which are also present on the OSN terminals) was able to suppress the synaptic mechanisms of OSNs (Wachowiak et al., 2005). Thus, the definitive role of dopamine $/ \mathrm{D}_{2} \mathrm{Rs}$ in presynaptic inhibition remains to be elucidated.

While not as much is known about the effects of $D_{1}$ Rs, its activity has been implicated in increasing odor detection (Doty et al., 1998), which contrasts with the effects of $\mathrm{D}_{2} \mathrm{R}$ (Doty and Risser, 1989). Interglomerular dopamine neurons also act upon 
distant ETCs (Liu et al., 2013). Dopamine and GABA release first act to inhibit the ETCs via the $\mathrm{GABA}_{\mathrm{A}} \mathrm{R}$, which activates the hyperpolarization-activated $\mathrm{I}_{\mathrm{H}}$ (Liu et al., 2013). Dopamine, which acts on a slower time course than GABA (Borisovska et al., 2013), further primes the $\mathrm{I}_{\mathrm{H}}$ current by activating the $\mathrm{D}_{1} \mathrm{R}$, causing rebound spiking in the ETCs (Liu et al., 2013). The $D_{1} R$ also indirectly inhibits M/TCs. Activating $D_{1} R$ on the inhibitory GCs inhibits their $\mathrm{GABA}_{\mathrm{A}}$ current, causing an increase in the feedforward inhibition to the M/TCs (Brünig et al., 1999). Lastly, unlike the retina, it is not known whether $D_{1}$ or $\mathrm{D}_{2}$ Rs affect the OB gap junctions, of which Cx36 specifically couples the dendrites of mitral cells (Christie and Westbrook, 2006). Given that $D_{1} R$ activation uncouples $C x 36$ gap junctions between the AII ACs in the retina (Kothmann et al., 2009), a similar or conserved mechanism may exist in the OB, but further studies are needed.

\section{PARKINSON'S DISEASE}

One of the most common neurodegenerative diseases, PD, is characterized by a progressive loss of dopaminergic neurons in the substantia nigra pars compacta $(\mathrm{SNc})$. Based on a metaanalysis that analyzed studies from 1985 to 2010 from around the world, the prevalence of PD increases with age and varies with location, with a higher prevalence seen in the 70-79-year age-group in North America, Europe, and Australia compared to Asia (Pringsheim et al., 2014). The most common symptoms of PD are motor disturbances (e.g., bradykinesia, tremors) (Carlsson, 1972), but non-motor disturbances are also present (Modugno et al., 2013), including disrupted sleep (Lima et al., 2007; Chaudhuri and Schapira, 2009; Lima, 2013; Rodrigues et al., 2014), prolactin cycling (Winkler et al., 2002), and circadian activity (Anderson and Maes, 2014; as reviewed by Korshunov et al., 2017), and even visual (Urwyler et al., 2014) and olfactory (Doty, 2012) disruptions occur. These symptoms may provide a clinical relevance to the neuromodulatory effects of dopamine in the retina and olfactory bulb.

\section{Visual Symptoms and Potential Impact of Retinal Dopamine Neurons}

Like in other mammalian species, dopamine neurons are present in the INL of human retinas (Frederick et al., 1982). In human patients, optical coherence tomography examinations determined that the INL was significantly thinner in patients with PD than in control subjects (Hajee et al., 2009). Dopaminergic innervation is reduced in patients with PD (Nguyen-Legros, 1988) and in retinas of postmortem patients with PD (Harnois and Di Paolo, 1990). Interestingly, the retinas of patients with PD who received L-DOPA treatment shortly before passing had a similar number of dopamine neurons compared to non-Parkinsonian retinas (Harnois and Di Paolo, 1990). These findings show that PD can have physiological impacts on the human retina and retinal dopamine neurons, but what are some potential symptoms that could arise from this?

Along with some commonly reported symptoms (e.g., hallucinations, double vision, and text moving while attempting to read) (Urwyler et al., 2014), visual symptoms in patients with PD also include deficits in color discrimination and contrast sensitivity, which tend to worsen with the progression of the disease (Price et al., 1992; Tagliati et al., 1996; Diederich et al., 2002). The electroretinogram (ERG) is a common electrophysiological technique that can identify these symptoms by examining the depolarizing response of the ON-BCs to light stimuli (commonly referred to as the b-wave). Clinical studies using this technique on patients (Bodis-Wollner et al., 1987; Price et al., 1992; Hutton et al., 1993) and animals (Onofrj and Bodis-Wollner, 1982; Bodis-Wollner, 1997) confirm that contrast sensitivity (the ability to distinguish one object from another) is affected significantly in subjects with PD. Amazingly, contrast sensitivity in people was also improved after L-DOPA treatment (Harnois and Di Paolo, 1990; Hutton et al., 1993; Peppe et al., 1998). These results may indicate that dopaminergic neurons that are impacted in Parkinsonian retinas are no longer able to decrease the receptive fields of various neurons by uncoupling them, potentially leading to decreased contrast sensitivity Additionally, these visual symptoms appeared to not be a co-morbidity of general motor symptoms, because patients who had non-Parkinsonian physical lesions to their basal ganglia did not experience these visual symptoms (Peppe et al., 1998).

While it is clear that there is some symptomatic impact of $\mathrm{PD}$ on the mammalian retina, it is important to also note that visual symptoms of PD can arise beyond the retina. For example, orientation-specific stimuli, which are processed by the visual cortex, are also impacted in PD (reviewed in Weil et al., 2016).

\section{Olfactory Symptoms and Potential Impact of Olfactory Bulb Dopamine Neurons}

Olfactory deficits (e.g., hyposmia and anosmia) are notable prodromal stages of PD that precede motor symptoms by years (Doty, 2012). In fact, non-motor smell tests are being encouraged to potentially diagnose PD before the emergence of motor symptoms (Berendse et al., 2001; Ponsen et al., 2004; Bohnen et al., 2008). These olfactory symptoms may result from impacted OB dopamine neurons. Paradoxically, dopamine neuron numbers in people with PD (Huisman et al., 2004; Mundiñano et al., 2011) and in Parkinsonian rodent models (Lelan et al., 2011) are dramatically higher. This increase may be part of a compensatory mechanism from the SVZ of rodents, where neurogenesis of $\mathrm{OB}$ dopamine neurons (related to olfactory recovery) occurred following traumatic brain injury (Marin et al., 2017). The reason for this increase in people with PD is not as clear. While it is originally thought that human OBs do not receive SVZ-derived neuroblasts, there is also evidence to the contrary (Bédard and Parent, 2004). Given that we and others have shown that $\mathrm{OB}$ dopamine acts as a presynaptic inhibitor of glutamate release from the OSNs (Nickell et al., 1994; Hsia et al., 1999; Berkowicz and Trombley, 2000; Ennis et al., 2001; Liu et al., 2013; Vaaga et al., 2017), and that increasing $\mathrm{D}_{2} \mathrm{R}$ activation can lead to a decrease in odor detection (Doty and Risser, 1989; Escanilla et al., 2009), it is likely that an increase in dopamine and 
$\mathrm{D}_{2} \mathrm{R}$ activity can lead to increased hyposmia and anosmia during the prodromal stages of PD (Huisman et al., 2004).

This research is ongoing, and recent studies are providing further insight (and potential inconsistencies) on the impacts of $\mathrm{PD}$ on the $\mathrm{OB}$. Transgenic mice with ablated vesicular monoamine transported 2 (VMAT2, a protein that allows dopamine to be packaged into vesicles)-expressing neurons displayed higher olfactory deficits (even though dopamine was reduced) and lower neurogenesis (Ma et al., 2019). Studies that ablate $\mathrm{OB}$ dopamine neurons with 6 hydroxydopamine (6OHDA, a common neurotoxin of dopaminergic neurons) show a similar decrease in olfaction (Höglinger et al., 2004; Ilkiw et al., 2019). Additionally, injection of 6-OHDA into the SNc dopaminergic neurons also decreased olfaction (Höglinger et al., 2015). This study is notable, because the authors report the first evidence of centrifugal dopaminergic innervation, stemming from the midbrain to the $\mathrm{OB}$ (Höglinger et al., 2015), which was previously reported not to exist. The authors mention that this decreased innervation is the primary cause of the symptoms. Thus, the mechanisms for olfactory symptoms in $\mathrm{PD}$ are complex, but likely involve some interplay between the $\mathrm{OB}$ and SNc dopamine neurons.

However, like the retina, olfactory impairments can stem beyond the $\mathrm{OB}$ (and the $\mathrm{SNc}$ ). One such study found that there is an increase in inflammatory activity of microglia in the PC (Sancandi et al., 2018). This indicates that the impact of PD on vision and olfaction are not just localized to the retina and OB. It is for the benefit of patients and for those at risk of developing PD to better understand these impacted mechanisms, to hopefully bring about a clinical foundation for better treatment.

\section{CONCLUSION}

Two of the arguably most crucial senses of the vertebrate world are vision, which is processed by the retina, and olfaction, which is processed by the OB. Whereas one area receives electromagnetic stimuli and the other chemical stimuli, once these stimuli are transduced into electrical pulses, the retina and OB become remarkably similar. For example, both areas process sensory signals by a sequential order of neurons embedded in distinct laminae, both areas utilize lateral inhibition, and both areas are affected by the well-known neuromodulator dopamine. Thus, dopamine is not only important for the study of addiction and movement disorders, but it is also a crucial component of visual and olfactory processing.

In this paper, we have reviewed the decades-old to brand new literature of dopamine's influence on the retina and $O B$, focusing on similarities of these structures that are otherwise functionally distinct. The morphology of dopamine neurons in both structures is heterogenous, and their identities are not completely agreed upon. The retinal dopamine neurons help maintain the autonomous circadian rhythmicity in the retina, while the value of the OB dopamine neurons to the bulb's circadian rhythm is yet to be determined. Both sets of neurons increase their dopamine synthesis and activity in response to light or olfactory stimuli, and both sets of neurons have various biophysical responses to different intensities of these stimuli. The neuromodulatory mechanisms of both retinal and $\mathrm{OB}$ dopamine neurons are complex, and they are crucial for mediating the transition from nighttime to daytime processing in the retina and for maintaining the odor threshold and discrimination in the OB. Several symptoms of PD, including decreased contrast sensitivity and increased hyposmia and anosmia, could very well be due to the dysregulation of these neuromodulatory effects of dopamine.

Overall, while the role of dopamine continues to be illuminated and sniffed out in the retina and $\mathrm{OB}$, respectively, there are many questions that remain to be answered. These questions also relate to the many potential differences between these two structures. What activates dopamine synthesis in neurons deep to the GL in the OB? While there is some evidence that dopamine neurons in the EPL can already receive excitatory synapses from the OSNs (Pignatelli et al., 2009), do other excitatory synapses influence the expression of $\mathrm{TH}$ in $\mathrm{OB}$ dopamine neurons? Furthermore, do these neurons exhibit other markers (besides a high intracellular $\mathrm{Cl}^{-}$concentration) that would make them immature (Pignatelli et al., 2009)? With new evidence that anaxonic, Small OB dopamine neurons are born postnatally (Galliano et al., 2018), are all deep OB dopamine neurons anaxonic? Whereas small, anaxonic subtypes of dopamine neurons in the $\mathrm{OB}$ continue to be generated throughout life, preliminary evidence (in fish) that some retinal dopamine neurons can regenerate after chemical ablation (Hitchcock and Vanderyt, 1994) also requires further investigation. What is the exact function of the Type-2 catecholamine/epinephrine neuron in the retina (Zhang et al., 2004), and are these neurons lost with age or is their expression of TH decreased (Wang et al., 1990)? Does dopamine in the OB influence the autonomous inner clock, like it does in the retina (Ruan et al., 2006, 2008)? What synaptic inputs regulate the activity of the retinal dopamine neurons that do not respond to light (Zhang et al., 2007)? How may the proposed dopaminergic input from the midbrain influence odor discrimination and other olfactory functions (Höglinger et al., 2015)? Lastly, how does dopamine affect glial cells, and how may this influence vision and olfaction? There is already evidence of $\mathrm{OB}$ astrocytes increasing their $\mathrm{Ca}^{2+}$ activity in response to the activation of $\mathrm{D}_{1}$ and $\mathrm{D}_{2} \mathrm{Rs}$ (Fischer et al., 2020), which is a fascinating note on which to end, because it implies that dopamine in the retina, OB, basal ganglia, and other brain areas would not only affect the neurons, but perhaps every type of brain cell.

\section{AUTHOR CONTRIBUTIONS}

KK and LB performed the literature search and review. KK wrote the first draft of the manuscript. LB and PT edited and contributed to all subsequent drafts. All authors agreed upon the final version of this manuscript.

\section{FUNDING}

This work was supported in part by the FSU Chemosensory Training Program (CTP) Grant 
Award T32 DC000044 from the National Institutes of Health (NIH/NIDCD) and NIH Grant R21DA044442.

\section{REFERENCES}

Abe, M., Herzog, E. D., Yamazaki, S., Straume, M., Tei, H., Sakaki, Y., et al. (2002). Circadian rhythms in isolated brain regions. J. Neurosci. 22, 350-356. doi: 10.1523/JNEUROSCI.22-01-00350.2002

Abraham, U., Prior, J. L., Granados-Fuentes, D., Piwnica-Worms, D. R., and Herzog, E. D. (2005). Independent circadian oscillations of Period1 in specific brain areas in vivo and in viro. J. Neurosci. 25, 8620-8626. doi: 10.1523/ JNEUROSCI.2225-05.2005

Akopian, A., and Witkovsky, P. (1996). D2 dopamine receptor-mediated inhibition of a hyperpolarization-activated current in rod photoreceptors. J. Neurophysiol. 76, 1828-1835. doi: 10.1152/jn.1996.76.3.1828

Alizadeh, R., Hassanzadeh, G., Soleimani, M., Joghataei, M. T., Siavashi, V., Khorgami, Z., et al. (2015). Gender and age related changes in number of dopaminergic neurons in adult human olfactory bulb. J. Chem. Neuroanat. 69 , 1-6. doi: 10.1016/j.jchemneu.2015.07.003

Alizadeh, R., Ramezanpour, F., Mohammadi, A., Eftekharzadeh, M., Simorgh, S., Kazemiha, M., et al. (2019). Differentiation of human olfactory systemderived stem cells into dopaminergic neuron-like cells: a comparison between olfactory bulb and mucosa as two sources of stem cells. J. Cell. Biochem. 120, 19712-19720. doi: 10.1002/jcb.29277

Anderson, G., and Maes, M. (2014). Neurodegeneration in Parkinson's disease: interactions of oxidative stress, tryptophan catabolites and depression with mitochondria and sirtuins. Mol. Neurobiol. 49, 771-783. doi: 10.1007/s12035013-8554-z

Aroniadou-Anderjaska, V., Zhou, F. M., Priest, C. A., Ennis, M., and Shipley, M. T. (2000). Tonic and synaptically evoked presynaptic inhibition of sensory input to the rat olfactory bulb via GABA(B) heteroreceptors. J. Neurophysiol. 84, 1194-1203. doi: 10.1152/jn.2000.84.3.1194

Aungst, J. L., Heyward, P. M., Puche, A. C., Karnup, S. V., Hayar, A., Szabo, G., et al. (2003). Centre-surround inhibition among olfactory bulb glomeruli. Nature 426, 623-629. doi: 10.1038/nature02185

Baker, H. (1990). Unilateral, neonatal olfactory deprivation alters tyrosine hydroxylase expression but not aromatic amino acid decarboxylase or GABA immunoreactivity. Neuroscience 26, 761-771. doi: 10.1016/0306-4522(90) 90018-y

Baker, H., Kawano, T., Albert, V., Joh, T. H., Reis, D. J., and Margolis, F. L. (1984). Olfactory bulb dopamine neurons survive deafferentation-induced loss of tyrosine hydroxylase. Neuroscience 11, 605-615. doi: 10.1016/0306-4522(84) 90047-2

Baker, H., Kawano, T., Margolis, F. L., and Joh, T. H. (1983). Transneuronal regulation of tyrosine hydroxylase expression in olfactory bulb of mouse and rat. J. Neurosci. 3, 69-78. doi: 10.1523/jneurosci.03-01-00069.1983

Baker, H., Liu, N., Chun, H. S., Saino, S., Berlin, R., Volpe, B., et al. (2001). Phenotypic differentiation during migration of dopaminergic progenitor cells to the olfactory bulb. J. Neurosci. 21, 8505-8513. doi: 10.1523/JNEUROSCI.2121-08505.2001

Bartell, P. A., Miranda-Anaya, M., McIvor, W., and Menaker, M. (2007). Interactions between dopamine and melatonin organize circadian rhythmicity in the retina of the green iguana. J. Biol. Rhythms 22, 515-523. doi: 10.1177/ 0748730407308167

Bédard, A., and Parent, A. (2004). Evidence of a newly generated neurons in the human olfactory bulb. Brain. Res. Dev. Brain. Res. 151, 159-168. doi: 10.1016/j. devbrainres.2004.03.021

Ben-Ari, Y., Gaiarsa, J. L., Tyzio, R., and Khazipov, R. (2007). GABA: a pioneer transmitter that excites immature neurons and generates primitive oscillations. Physiol. Rev. 87, 1215-1284. doi: 10.1152/physrev.000 17.2006

Berendse, H. W., Booij, J., Francot, C. M. J. E., Bergmans, P. L. M., Hijman, R., Stoof, J. C., et al. (2001). Subclinical dopaminergic dysfunction in asymptomatic Parkinson's disease patients' relatives with a decreased sense of smell. Ann. Neurol. 50, 34-41. doi: 10.1002/ana.1049

\section{ACKNOWLEDGMENTS}

We thank Charles Badland for his help with all the figures.

Berkowicz, D. A., Trombley, P. Q., and Shepherd, G. M. (1994). Evidence for glutamate as the olfactory receptor cell neurotransmitter. J. Neurophysiol. 71, 2557-2561. doi: 10.1152/jn.1994.71.6.2557

Berkowicz, D. A., and Trombley, P. Q. (2000). Dopaminergic modulation at the olfactory nerve synapse. Brain. Res. 855, 90-99. doi: 10.1016/s0006-8993(99) 02342-2

Berson, D. M., Dunn, F. A., and Takao, M. (2002). Phototransduction by retinal ganglion cells that set the circadian clock. Science 295, 1070-1073. doi: 10.1126/ science. 1067262

Besharse, J. C., and Iuvone, P. M. (1983). Circadian clock in Xenopus eye controlling retinal serotonin $\mathrm{N}$-acetyltransferase. Nature 305, 133-135. doi: 10.1038/305133a0

Bettler, B., Kaupmann, K., Mosbacher, J., and Gassmann, M. (2004). Molecular structure and physiological functions of GABA(B) receptors. Physiol. Rev. 84, 835-867. doi: 10.1152/physrev.00036.2003

Boatright, J. H., Rubim, N. M., and Iuvone, P. M. (1994). Regulation of endogenous dopamine release in amphibian retina by melatonin: the role of GABA. Vis. Neurosci. 11, 1013-1018. doi: 10.1017/s0952523800 003941

Bodis-Wollner, I. (1997). Visual electrophysiology in Parkinson's disease: PERG, VEP and visual P300. Clin. Electroencephalogr. 28, 143-147. doi: 10.1177/ 155005949702800305

Bodis-Wollner, I., Marx, M. S., Mitra, S., Bobak, P., Mylin, L., and Yahr, M. (1987). Visual dysfunction in Parkinson's disease. Loss in spatiotemporal contrast sensitivity. Brain 110, 1675-1698. doi: 10.1093/brain/110.6.1675

Bohnen, N. I., Studenski, S. A., Constantine, G. M., and Moore, R. Y. (2008). Diagnostic performance of clinical motor and non-motor tests of Parkinsonian disease: A matched case-control study. Eur. J. Neurol. 15, 685-691. doi: 10.1111/ j.1468-1331.2008.02148.x

Borisovska, M., Bensen, A. L., Chong, G., and Westbrook, G. L. (2013). Distinct modes of dopamine and GABA release in dual transmitter neuron. J. Neurosci. 33, 1790-1796. doi: 10.1523/JNEUROSCI.4342-12.2013

Boto, T., Louis, T., Jindachomthong, K., Jalink, K., and Tomchik, S. M. (2014). Dopaminergic modulation of cAMP drives nonlinear plasticity across the Drosophilla mushroom body lobes. Curr. Biol. 24, 822-831. doi: 10.1016/j.cub. 2014.03.021

Brainard, G. C., and Morgan, W. W. (1987). Light-induced stimulation of retinal dopamine: a dose-response relationship. Brain Res. 424, 199-203. doi: 10.1016/ 0006-8993(87)91211-x

Brünig, I., Sommer, M., Hatt, H., and Bormann, J. (1999). Dopamine receptor subtypes modulate olfactory bulb gamma-aminobutyric acid A receptors. Proc. Natl. Acad. Sci. U.S.A. 96, 2456-2460. doi: 10.1073/pnas.96. 5.2456

Bundschuh, S. T., Zhu, P., Schärer, Y. P. Z., and Friedrich, R. W. (2012). Dopaminergic modulation of mitral cells and odor responses in the zebrafish olfactory bulb. J. Neurosci. 32, 6830-6840. doi: 10.1523/JNEUROSCI.6026-11. 2012

Cahill, G. M., and Besharse, J. C. (1993). Circadian clock function localized in Xenopus retinal photoreceptors. Neuron 10, 573-577. doi: 10.1016/08966273(93)90160-s

Cahill, G. M., Grace, M. S., and Besharse, J. C. (1991). Rhythmic regulation of retinal melatonin: metabolic pathways, neurochemical mechanisms, and the ocular circadian clock. Cell. Mol. Neurobiol. 11, 529-560. doi: 10.1007/ BF00734814

Carlsson, A. (1972). Biochemical and pharmacological aspects of Parkinsonism. Acta. Neurol. Scand. Suppl. 51, 11-42.

Cave, J. W., and Baker, H. (2009). Dopamine systems in the forebrain. Adv. Exp. Med. Biol. 651, 15-35. doi: 10.1007/978-1-4419-0322-8_2

Chand, A. N., Galliano, E., Chesters, R. A., and Grubbs, M. S. (2015). A distinct subtype of dopaminergic interneuron displays inverted structural plasticity at the axon initial segment. J. Neurosci. 35, 1573-1590. doi: 10.1523/JNEUROSCI. 3515- 14.2015 
Chaudhuri, K. R., and Schapira, A. H. V. (2009). Non-motor symptoms of Parkinson's disease: dopaminergic pathophysiology and treatment. Lancet Neurol. 8, 464-474. doi: 10.1016/S1474-4422(09)70068-7

Chen, L., and Yang, X. L. (2007). Hyperpolarization-activated cation current is involved in modulation of the excitability of rat retinal ganglion cells by dopamine. Neuroscience 150, 299-308. doi: 10.1016/j.neuroscience.2007. 09.015

Christie, J. M., and Westbrook, G. L. (2006). Lateral excitation within the olfactory bulb. J. Neurosci. 26, 2269-2277. doi: 10.1523/JNEUROSCI.4791-05.2006

Cigola, E., Volpe, B. T., Lee, J. W., Franzen, L., and Baker, H. (1998). Tyrosine hydroxylase expression in primary cultures of olfactory bulb: role of L-type calcium channels. J. Neurosci. 18, 7638-7649. doi: 10.1523/jneurosci.18-1907638.1998

Contini, M., and Raviola, E. (2003). GABAergic synapses made by a retinal dopaminergic neuron. Proc. Natl. Acad. Sci. U.S.A. 100, 1358-1363. doi: 10. 1073/pnas.0337681100

Contini, M., Lin, B., Kobayashi, K., Oklano, H., Masland, R. H., and Raviola, E. (2010). Synaptic input of ON-bipolar cells onto the dopaminergic neurons of the mouse retina. J. Comp. Neurol. 518, 2035-2050. doi: 10.1002/cne.22320

Coopersmith, R., Weihmuller, F. B., Kristein, C. L., Marshall, J. F., and Leon, M. (1991). Extracellular dopamine increases in the neonatal olfactory bulb during odor preference training. Brain Res. 564, 149-153. doi: 10.1016/0006-8993(91) 91365-8

Coronas, V., Srivastava, L. K., Liang, J. J., Jourdan, F., and Moyse, E. (1997). Identification and localization of dopamine receptor subtypes in rat olfactory bulb mucosa and bulb: a combined in situ hybridization and ligand binding radioautographic approach. J. Chem. Neuroanat. 12, 243-257. doi: 10.1016/ s0891-0618(97)00215-9

Corthell, J. T., Olcese, J., and Trombley, P. Q. (2014). Melatonin in the mammalian olfactory bulb. Neuroscience 261, 74-84. doi: 10.1016/j.neuroscience.2013.12. 033

Corthell, J. T., Stathopoulos, A. M., Watson, C. C., Bertram, R., and Trombley, P. Q. (2013). Olfactory bulb monoamine concentrations vary with time of day. Neuroscience 247, 234-241. doi: 10.1016/j.neuroscience.2013. 05.040

Dacks, A. M., Riffell, J. A., Martin, J. P., Gage, S. L., and Nighorn, A. J. (2012). Olfactory modulation by dopamine in the context of aversive learning. J. Neurophysiol. 108, 539-550. doi: 10.1152/jn.00159.2012

Davila, N. G., Blakemore, L. B., and Trombley, P. Q. (2003). Dopamine modulates synaptic transmission between rat olfactory bulb neurons in culture. J. Neurophysiol. 90, 395-404. doi: 10.1152/jn.01058.2002

Davis, B. J., and Macrides, F. (1983). Tyrosine hydroxylase immunoreactive neurons and fibers in the olfactory system of the hamster. J. Comp. Neurol. 214, 427-440. doi: 10.1002/cne/902140407

Davison, I. G., Boyd, J. D., and Delaney, K. R. (2004). Dopamine inhibits mitral/tufted $\diamond$ granule cell synapses in the frog olfactory bulb. J. Neurosci. 24, 8057-8067. doi: 10.1523/JNEUROSCI.2138-04.2004

Demb, J. B., and Singer, J. H. (2012). Intrinsic properties and functional circuitry of the AII amacrine cell. Vis. Neurosci. 29, 51-60. doi: 10.1017/ S0952523811000368

DeVries, S. H., Qi, X., Smith, R., Makous, W., and Sterlin, P. (2002). Electrical coupling between mammalian cones. Curr. Biol. 12, 1900-1907. doi: 10.1016/ s0960-9822(02)01261-7

Dhande, O. S., and Huberman, A. D. (2014). Retinal ganglion cell maps in the brain: implications for visual processing. Curr. Opn. Neurobiol. 24, 133-142. doi: 10.1016/j.conb.2013.08.006

Diederich, N. J., Raman, R., Leurgans, S., and Goetz, C. G. (2002). Progressive worsening of spatial and chromatic processing deficits in Parkinson disease. Arch. Neurol. 59, 1249-1252. doi: 10.1001/archneur.59.8.1249

Dkhissi-Benyahya, O., Coutanson, C., Knoblauch, K., Lahouaoui, H., Leviel, V., Rey, C., et al. (2013). The absence of melanopsin alters retinal clock function and dopamine regulation by light. Cell. Mol. Life Sci. 70, 3435-3447. doi: 10. 1007/s00018-013-1338-9

Doty, R. L. (2012). Olfaction in Parkinson's disease and related disorders. Neurobiol. Dis. 46, 527-552. doi: 10.1016/j.nbd.2011.10.026

Doty, R. L., Li, C., Bagla, R., Huang, W., Pfeiffer, C., Brosvic, G. M., et al. (1998). SKF 38393 enhances odor detection performance. Psychopharmacology 136, 75-82. doi: 10.1007/s002130050541
Doty, R. L., and Risser, J. M. (1989). Influence of the D-2 dopamine receptor agonist quinpirole on the odor detection performance of rats before and after spiperone administration. Psychopharmacology 98, 310-315. doi: 10.1007/bf00451680

Doyle, S. E., Grace, M. S., McIvor, W., and Menaker, M. (2002a). Circadian rhythmicity of dopamine in mouse retina: the role of melatonin. Vis. Neurosci. 19, 593-601. doi: 10.1017/s0952523802195058

Doyle, S. E., McIvor, W. E., and Menaker, M. (2002b). Circadian rhythmicity in dopamine content of mammalian retina: role of the photoreceptors. J. Neurochem. 83, 211-219. doi: 10.1046/j.1471-4159.2002.01149.x

Duchamp-Viret, P., Coronas, V., Delaleu, J. C., Moyse, E., and Duchamp, A. (1997). Dopaminergic modulation of mitral cell activity in the frog olfactory bulb: a combined radioligand binding-electrophysiological study. Neuroscience 79, 203-216. doi: 10.1016/s0306-4522(96)00646-x

Dumitrescu, O. N., Pucci, F. G., Wong, K. Y., and Berson, D. M. (2009). Ectopic retinal ON bipolar cell synapses in the OFF inner plexiform layer: contracts with dopaminergic amacrine cells and melanopsin ganglion cells. J. Comp. Neurol. 517, 226-244. doi: 10.1002/cne.22158

Ennis, M., Hamilton, K. A., and Hayar, A. (2007). "Neurochemistry of the main olfactory system," in Handbook of Neurochemistry and Molecular Neurobiology, eds A. Lajtha and D. A. Joohnson (Boston, MA: Springer). doi: 10.1007/978-0387-30374-1_6

Ennis, M., Puche, A. C., Holy, T., and Shipley, M. T. (2015). “The olfactory system," in The Rat Nervous System, 4th Edn, ed. G. Paxinos (Cambridge, MA: Academic Press), 761-803. doi: 10.1016/B978-0-12-374245-2.00027-9

Ennis, M., Zhou, F. M., Ciombor, K. J., Aroniadou-Anderjaska, V., Hayar, A., Borrelli, E., et al. (2001). Dopamine D2 receptor-mediated presynaptic inhibition of olfactory nerve terminals. J. Neurophysiol. 86, 2986-2997. doi: 10.1152/jn.2001.86.6.2986

Ennis, M., Zimmer, L. A., and Shipley, M. T. (1996). Olfactory nerve stimulation activates rat mitral cells via NMDA and non-NMDA receptors in vitro. Neuroreport 7, 989-992. doi: 10.1097/00001756-199604100-00007

Escanilla, O., Yuhas, C., Marzan, D., and Linster, C. (2009). Dopaminergic modulation of olfactory bulb processing affects odor discrimination learning in rats. Behav. Neurosci. 123, 828-833. doi: 10.1037/a0015855

Feigenspan, A., Gustincich, S., Bean, B. P., and Raviola, E. (1998). Spontaneous activity of solitary dopaminergic cells of the retina. J. Neurosci. 18, 6776-6789. doi: 10.1523/jneurosci.18-17-06776.1998

Felten, D. L., and Sladek, J. R. Jr. (1983). Monoamine distribution in primate brain V. Monoaminergic nuclei: anatomy, pathways and local organization. Brain. Res. Bull. 10, 171-284. doi: 10.1016/0361-9230(83)90045-x

Fischer, T., Scheffler, P., and Lohr, C. (2020). Dopamine-induced calcium signaling in olfactory bulb astrocytes. Sci. Rep. 10:631. doi: 10.1038/s41598-020-57462-4

Flood, M. D., Moore-Dotson, J. M., and Eggers, E. D. (2018). Dopamine D1 receptor activation contributes to light-adapted changes in retinal inhibition to rod bipolar cells. J. Neurophysiol. 120, 867-879. doi: 10.1152/jn.00855.2017

Frederick, J. M., Rayborn, M. E., Laties, A. M., Lam, D. M., and Hollyfield, J. G. (1982). Dopaminergic neurons in the human retina. J. Comp. Neurol. 210, 65-79. doi: 10.1002/cne.902100108

Gall, C. M., Hendry, S. H., Seroogy, K. B., Jones, E. G., and Haycock, J. W. (1987). Evidence for coexistence of GABA and dopamine in neurons of the rat olfactory bulb. J. Comp. Neurol. 266, 307-318. doi: 10.1002/cne.902660302

Galliano, E., Franzoni, E., Breton, M., Chand, A. N., Byrne, D. J., Murthy, V. N., et al. (2018). Embryonic and postnatal neurogenesis produce functionally distinct subclasses of dopaminergic neuron. eLife 7:e32373. doi: 10.7554/eLife. 32373

Godley, B. F., and Wurtman, R. J. (1988). Release of endogenous dopamine from the superfused rabbit retina in vitro: effect of light stimulation. Brain Res. 452, 393-395. doi: 10.1016/0006-8993(88)90046-7

Granados-Fuentes, D., Ben-Josef, G., Perry, G., Wilson, D. A., Sullivan-Wilson, A., and Herzog, E. D. (2011). Daily rhythms in olfactory discrimination depend on clock genes but not the suprachiasmatic nucleus. J. Biol. Rhythms. 26, 552-560. doi: 10.1177/0748730411420247

Granados-Fuentes, D., Prolo, L. M., Abraham, U., and Herzog, E. D. (2004a). The suprachiasmatic nucleus entrains, but does not sustain, circadian rhythmicity in the olfactory bulb. J. Neurosci. 24, 615-619. doi: 10.1523/JNEUROSCI.400203.2004

Granados-Fuentes, D., Saxena, M. T., Prolo, L. M., Aton, S. J., and Herzog, E. D. (2004b). Olfactory bulb neurons express functional, entrainable 
circadian rhythms. Eur. J. Neurosci. 19, 898-906. doi: 10.1111/j.0953-816x.2004. 03117.x

Granados-Fuentes, D., Tseng, A., and Herzog, E. D. (2006). A circadian clock in the olfactory bulb controls olfactory responsivity. J. Neurosci. 26, 12219-12225. doi: 10.1523/JNEUROSCI.3445-06.2006

Gross, C. G. (2000). Neurogenesis in the adult brain: Death of a dogma. Nat. Rev. Neurosci. 1, 67-73. doi: 10.1038/35036235

Grier, B. D., Belluscio, L., and Cheetham, C. E. J. (2016). Olfactory sensory activity modulates microglial-neuronal interactions during dopaminergic cell loss in the olfactory bulb. Front. Cell. Neurosci. 10:178. doi: 10.3389/fncel.2016.00178

Gustincich, S., Feigenspan, A., Wu, D. K., Koopman, L. J., and Raviola, E. (1997). Control of dopamine release in the retina: a transgenic approach to neural networks. Neuron 18, 723-736. doi: 10.1016/s0896-6273(00)80313-x

Guthrie, K. M., Pullara, J. M., Marshall, J. F., and Leon, M. (1991). Olfactory deprivation increases dopamine $\mathrm{D}_{2}$ receptor density in the rat olfactory buln. Synapse 8, 61-70. doi: 10.1002/syn.890080109

Guthrie, K. M., Wilson, D. A., and Leon, M. (1990). Early unilateral deprivation modifies olfactory bulb function. J. Neurosci. 10, 3402-3412. doi: 10.1523/ JNEUROSCI.10-10-03402.1990

Gutièrrez-Mecinas, M., Crespo, C., Blasco-Ibáñez, J. M., Gracia-Llanes, F. J., Marqués-Marí, A. I., and Nácher, J. (2005). Distribution of D2 dopamine receptor in the olfactory glomeruli of the rat olfactory bulb. Eur. J. Neurosci. 22, 1357-1367. doi: 10.1111/j.1460-9568.2005.04328.x

Hack, M. A., Saghatelyan, A., de Chevigny, A., Pfeifer, A., Ashery-Padan, R., Lledo, P. M., et al. (2005). Neuronal fate determinants of adult olfactory bulb neurogenesis. Nat. Neurosci. 8, 865-872. doi: 10.1038/nn1479

Hadjiconstantinou, M., Cohen, J., and Neff, N. H. (1983). Epinephrine: a potential neurotransmitter in retina. J. Neurochem. 41, 1440-1444. doi: 10.1111/j.14714159.1983.tb00843.x

Hajee, M. E., March, W. F., Lazzaro, D. R., Wolintz, A. H., Shrier, E. M., Glazman, S., et al. (2009). Inner retinal layer thinning in Parkinson disease. Arch. Ophthalmol. 127, 737-741. doi: 10.1001/archophthalmol.2009.106

Halász, N., Johansson, O., Hökfelt, T., Ljunghahl, A., and Goldstein, A. (1981). Immunohistochemical identification of two types of dopamine neuron in the rat olfactory bulb as seen by serial sectioning. J. Neurocytol. 10, 251-259. doi: $10.1007 /$ bf01257970

Hampson, E. C., Vaney, D. I., and Weiler, R. (1992). Dopaminergic modulation of gap junction permeability between amacrine cells in mammalian retina. J. Neurosci. 12, 4911-4922. doi: 10.1523/JNEUROSCI.12-12-04911.1992

Harnois, C., and Di Paolo, T. (1990). Decreased dopamine in the retinas of patients with Parkinson's disease. Invest. Opththalmol. Vis. Sci. 31, 2473-2475.

Harsanyi, K., and Mangel, S. C. (1992). Activation of a $\mathrm{D}_{2}$ receptor increases electrical coupling between horizontal cells by inhibiting dopamine release. Proc. Natl. Acad. Sci. U.S.A. 89, 9220-9224. doi: 10.1073/pnas.89. 19.9220

Hattar, S., Liao, H. W., Takao, M., Berson, D. M., and Yau, K. W. (2002). Melanopsin-containing retinal ganglion cells: architecture, projections, and intrinsic photosensitivity. Science 295, 1065-1070. doi: 10.1126/science. 1069609

Hattar, S., Lucas, R. J., Mrosovsky, N., Thompson, S., Douglas, R. H., Hankins, M. W., et al. (2003). Melanopsin and rod-cone photoreceptive systems account for all major accessory visual functions in mice. Nature 424, 76-81. doi: 10.1038/ nature 01761

Hayar, A., Karnup, S., Ennis, M., and Shipley, M. T. (2004). External tufted cells: a major excitatory element that coordinates glomerular activity. J. Neurosci. 24, 6676-6685. doi: 10.1523/JNEUROSCI.1367-04.2004

Hayashida, Y., and Ishida, A. T. (2004). Dopamine receptor activation can reduce voltage-gated $\mathrm{Na}^{+}$current by modulating both entry into and recovery from inactivation. J. Neurophysiol. 92, 3134-3141. doi: 10.1152/jn.005 26.2004

Hayashida, Y., Rodriguez, C. V., Ogata, G., Partida, G. J., Oi, H., Stardeigh, T. W., et al. (2009). Inhibition of adult rat retinal ganglion cells by D1-type dopamine receptor activation. J. Neurosci. 29, 15001-15016. doi: 10.1523/JNEUROSCI. 3827-09.2009

Hirasawa, H., Puopolo, M., and Raviola, E. (2009). Extrasynaptic release of GABA by retinal dopaminergic neurons. J. Neurophysiol. 102, 146-158. doi: 10.1152/ jn.00130.2009
Hitchcock, P. F., and Vanderyt, J. T. (1994). Regeneration of the dopamine-cell mosaic in the retina of the goldfish. Vis. Neurosci. 11, 209-217. doi: 10.1017/ s0952523800001577

Höglinger, G. U., Alvarez-Fischer, D., Arias-Carrión, O., Djufri, M., Windolph, A., Keber, U., et al. (2015). A new dopaminergic nigro-olfactory projection. Acta Neuropathol. 130, 333-348. doi: 10.1007/s00401-015-1451-y

Höglinger, G. U., Rizk, P., Muriel, M. P., Duyckaerts, C., Oertel, W. H., Caille, I., et al. (2004). Dopamine depletion impairs precursor cell proliferation in Parkinson disease. Nat. Neurosci. 7, 726-735. doi: 10.1038/nn1265

Hökfelt, T., Martensson, R., Björklund, A., Kheinau, S., and Goldstein, M. (1984). "Distribution maps of tyrosine-hydroxylase-immunoreactive neurons in the rat brain," in Handbook of Chemical Neuroanatomy. (Classical Transmitters in the CNS, Part I, eds A. Björklund and T. Hökfelt (Amsterdam: Elsevier), 277-379.

Hoshi, H., Liu, W. L., Massey, S. C., and Mills, S. L. (2009). ON inputs to the OFF sublayer: bipolar cells that break the stratification rules of the retina. J. Neurosci. 29, 8875-8883. doi: 10.1523/JNEUROSCI.0912-09.2009

Hsia, A. Y., Vincent, J. D., and Lledo, P. M. (1999). Dopamine depresses synaptic inputs into the olfactory bulb. J. Neurophysiol. 82, 1082-1085. doi: 10.1152/jn. 1999.82.2.1082

Hu, E. H., Pan, F., Völgyi, B., and Bloomfield, S. A. (2010). Light increases the gap junctional coupling of retinal ganglion cells. J. Physiol. 588( $\mathrm{Pt} 21), 4145-4163$. doi: 10.1113/jphysiol.2010.193268

Huisman, E., Uylings, H. B. M., and Hoogland, P. V. (2004). A 100\% increase of dopaminergic cells in the olfactory bulb may explain hyposmia in Parkinson's disease. Mov. Dis. 19, 687-692. doi: 10.1002/mds.10713

Husse, J., Eichele, G., and Oster, H. (2015). Synchronization of the mammalian circadian timing system: light can control peripheral clocks independently of the SCN Clock: alternate routes of entrainment optimize the alignment of the body's circadian clock network with external time. Bioessays 37, 1119-1128. doi: 10.1002/bies.201500026

Hutton, J. T., Morris, J. L., and Elias, J. W. (1993). Levodopa improves spatial contrast sensitivity in Parkinson's disease. Arch. Neurol. 50, 721-724. doi: 10. 1001/archneur.1993.00540070041012

Hwang, C. K., Chaurasia, S. S., Jackson, C. R., Chan, G. C. K., Storm, D. R., and Iuvone, P. M. (2013). Circadian rhythm of contrast sensitivity is regulated by a dopamine-neuronal PAS-domain Protein 2-adenylyl cyclase 1 signaling pathway in retinal ganglion cells. J. Neurosci. 33, 14989-14997. doi: 10.1523/ JNEUROSCI.2039-13.2013

Iacovitti, L., Wei, X., Cai, J., Kostuk, E. W., Lin, R., Gorodinsky, A., et al. (2014). The hTH-GFP rat model for the study of Parkinson's disease. PLoS One 9:e113151. doi: 10.1371/journal.pone.0113151

Ilkiw, J. L., Kmita, L. C., Targa, A. D. S., Noseda, A. C. D., Rodrigues, L. S., Dorieux, F. W. C., et al. (2019). Dopaminergic lesion in the olfactory bulb restores olfaction and induces depressive-like behaviors in a 6-OHDA model of Parkinson's disease. Mol. Neurobiol. 56, 1082-1095. doi: 10.1007/s12035-0181134-5

Isaacson, J. S., and Strowbridge, B. W. (1998). Olfactory reciprocal synapses: dendritic signaling in the CNS. Neuron 20, 749-761. doi: 10.1016/s08966273(00)81013-2

Iuvone, P. M. (1984). Regulation of retinal dopamine biosynthesis and tyrosine hydroxylase activity by light. Fed. Proc. 43, 2709-2713.

Iuvone, P. M. (1986). Evidence for a $\mathrm{D}_{2}$ dopamine receptor in frog retina that decreases cyclic AMP accumulation and serotonin $\mathrm{N}$-acetyltransferase activity. Life. Sci. 38, 331-342. doi: 10.1016/0024-3205(86)90080-9

Jackson, C. R., Chaurasia, S. S., Hwang, C. K., and Iuvone, P. M. (2011). Dopamine $\mathrm{D}_{4}$ receptor activation controls circadian timing of the adenylyl cyclase $1 /$ cyclic AMP signaling system in mouse retina. Eur. J. Neurosci. 34, 57-64. doi: 10.1111/ j.1460-9568.2011.07734.x

Jackson, C. R., Chaurasia, S. S., Zhou, H., Haque, R., Storm, D. R., and Iuvone, P. M. (2009). Essential roles of dopamine $D_{4}$ receptors and the type 1 adenylyl cyclase in photic control of cyclic AMP in photoreceptor cells. J. Neurochem. 109, 148-157. doi: 10.1111/j.1471-4159.2009/05920.x

Jackson, C. R., Ruan, G. X., Aseem, F., Abey, J., Gamble, K., Stanwood, G., et al. (2012). Retinal dopamine mediates multiple dimensions of light-adapted vision. J. Neurosci. 32, 9359-9368. doi: 10.1523/JNEUROSCI.0711-12.2012

Jacobs, G. H., Neitz, J., and Deegan, J. F. II (1991). Retinal receptors in rodents maximally sensitive to ultraviolet light. Nature 353, 655-656. doi: 10.1038/ $353655 \mathrm{a} 0$ 
Jeon, C. J., Strettoi, E., and Masland, R. H. (1998). The major cell populations of the mouse retina. J. Neurosci. 18, 8936-8946. doi: 10.1523/JNEUROSCI.18-2108936.1998

Jin, N. G., Chuang, A. Z., Masson, P. J., and Ribelayga, C. P. (2015). Rod electrical coupling is controlled by a circadian clock and dopamine in mouse retina. J. Physiol. 593, 1597-1631. doi: 10.1113/jphysiol.2014.284919

Kawai, F., Horiguchi, M., and Miyachi, E. (2011). Dopamine modulates the voltage response of human rod photoreceptors by inhibiting the h current. Invest. Opthalmol. Vis. Sci. 52, 4113-4117. doi: 10.1167/iovs.10-6983

Kiyokage, E., Pan, Y. Z., Shao, Z., Kobayashi, K., Szabo, G., Yanagawa, Y., et al. (2010). Molecular identity of periglomerular and short axon cells. J. Neurosci. 30, 1185-1196. doi: 10.1523/JNEUROSCI.3497-09.2010

Koistinaho, J., and Sagar, S. M. (1995). Light-induced c-Fos expression in amacrine cells in the rabbit retina. Brain Res. Mol. Brain Res. 29, 53-63. doi: 10.1016/0169$328 \mathrm{x}(94) 00218-4$

Korshunov, K. S., Blakemore, L. J., and Trombley, P. Q. (2017). Dopamine: a modulator of circadian rhythms in the central nervous system. Front. Cell. Neurosci. 11:91. doi: 10.3389/fncel.2017.00091

Korshunov, K. S., Blakemore, L. J., Bertram, R., and Trombley, P. Q. (2020). Spiking and membrane properties of rat olfactory bulb dopamine neurons. Front. Cell. Neurosci. 14:60. doi: 10.3389/fncel.2020.00060

Kosaka, K., Aika, Y., Toida, K., Heizmann, C. W., Hunziker, W., Jacobowitz, D. M., et al. (1995). Chemically defined neuron groups and their subpopulations in the glomerular layer of the rat main olfactory bulb. Neurosci. Res. 23, 73-88. doi: 10.1016/0168-0102(95)90017-9

Kosaka, K., and Kosaka, T. (2004). Organization of the main olfactory bulbs of some mammals: musk shrews, moles, hedgehogs, tree shrews, bats, mice, and rats. J. Comp. Neurol. 472, 1-12. doi: 10.1002/cne.20004

Kosaka, K., and Kosaka, T. (2005). Synaptic organization of the glomerulus in the main olfactory bulb: compartments of the glomerulus and heterogeneity of periglomerular cells. Anat. Sci. Int. 80, 80-90. doi: 10.1111/j.1447-073x.2005. 00092.x

Kosaka, K., and Kosaka, T. (2007). Chemical properties of type 1 and type 2 periglomerular cells in the mouse olfactory bulb are different from those in the rat olfactory bulb. Brain Res. 1167, 42-55. doi: 10.1016/j.brainres.2007.04.087

Kosaka, K., Hama, K., Nagatsu, I., Wu, J. Y., Ottersen, O. P., StormMathisen, J., et al. (1987). Postnatal development of neurons containing both catecholaminergic and GABAergic traits in the rat main olfactory bulb. Brain Res. 403, 355-360. doi: 10.1016/0006-8993(87)90075-8

Kosaka, K., Toida, K., Aika, Y., and Kosaka, T. (1998). How simple is the organization of the olfactory glomerulus?: the heterogeneity of so-called periglomerular cells. Neurosci. Res. 30, 101-110. doi: 10.1016/s0168-0102(98) 00002-9

Kosaka, K., Toida, K., Margolis, F. L., and Kosaka, T. (1997). Chemically defined neuron group groups and their subpopulations in the glomerular layer of the rat main olfactory bulb - II. Prominent differences in the intraglomerular dendritic arborization and their relationship to olfactory nerve terminals. Neuroscience 76, 775-786. doi: 10.1016/s0306-4522(96)00308-9

Kosaka, T., and Kosaka, K. (2008). Tyrosine hydroxylase-positive GABAergic juxtaglomerular neurons are the main source of the interglomerular connections in the mouse main olfactory bulb. Neurosci. Res. 60, 349-354. doi: 10.1016/j.neures.2007.11.012

Kosaka, T., and Kosaka, K. (2009). Two types of tyrosine hydroxylase positive GABAergic juxtaglomerular neurons in the mouse main olfactory bulb are different in their time of origin. Neurosci. Res. 64, 436-441. doi: 10.1016/j. neures.2009.04.018

Kosaka, T., and Kosaka, K. (2011). "Interneurons" in the olfactory bulb revisited. Neurosci. Res. 69, 93-99. doi: 10.1016/j.neures.2010.10.002

Kosaka, T., and Kosaka, K. (2016). Neuronal organization of the main olfactory bulb revisited. Anat. Sci. Int. 91, 115-127. doi: 10.1007/s12565-0150309-7

Kosaka, T., Hataguchi, Y., Hama, K., Nagatsu, I., and Wu, J. Y. (1985). Coexistence of immunoreactivities for glutamate decarboxylase and tyrosine hydroxylase in some neurons in the periglomerular region of the rat main olfactory bulb: possible coexistence of gamma-aminobutyric acid (GABA) and dopamine. Brain Res. 343, 166-171. doi: 10.1016/0006-8993(85) 91172-2
Kosaka, T., Pignatelli, A., and Kosaka, K. (2019). Heterogeneity of tyrosine hydroxylase expressing neurons in the main olfactory bulb. Neurosci. Res. (in press). doi: 10.1016/j.neures.2019.10.004

Koster, N. L., Norman, A. B., Richtand, N. M., Nickell, W. T., Puche, A. C., Pixley, S. K., et al. (1999). Olfactory receptor neurons express $\mathrm{D}_{2}$ dopamine receptors. J. Comp. Neurol. 411, 666-673. doi: 10.1002/(sici)1096-9861(19990906)411: $4<666$ ::aid-cne10<3.0.co;2-s

Kothmann, W. W., Stephen, C. M., and O’Brien, J. (2009). Dopamine-stimulated dephosphorylation of connexin 36 mediates AII amacrine cell uncoupling. J. Neurosci. 29, 14903-14911. doi: 10.1523/JNEUROSCI.3436-09.2009

Kratskin, I., and Belluzzi, O. (2003). "Anatomy and neurochemistry of the olfactory bulb," in Handbook of Olfaction and Gustation, ed. R. L. Doty (New York, NY: Marcel Dekker), 139-164.

Lelan, F., Boyer, C., Thinard, R., Remy, S., Usal, C., Tesson, L., et al. (2011). Effects of human alpha-synuclein A53T-A30P mutation on SVZ and local olfactory bulb cell proliferation in a transgenic rat model of Parkinson's disease. Parkinsons. Dis. 2011:987084. doi: 10.4061/2011/987084

Levey, A. I., Hersch, S. M., Rye, D. B., Sunahara, R. K., Niznik, H. B., Kitt, C. A., et al. (1993). Localization of $D_{1}$ and $D_{2}$ dopamine receptors in brain with subtype-specific antibodies. Proc. Natl. Acad. Sci. U.S.A. 90, 8861-8865. doi: $10.1073 /$ pnas.90.19.8861

Li, H., Chuang, A. Z., and O’Brien, J. (2014). Regulation of photoreceptor gap junction phosphorylation by adenosine in zebrafish retina. Vis. Neurosci. 31, 237-243. doi: 10.1017/S095252381300062X

Li, H., Zhang, Z., Blackburn, M. R., Wang, S. W., Ribelayga, C. P., and O’Brien, J. (2013). Adenosine and dopamine receptors coregulate photoreceptor coupling via gap junction phosphorylation in mouse retina. J. Neurosci. 33, 3135-3150. doi: 10.1523/JNEUROSCI.2807-12.2013

Lima, M. M. S. (2013). Sleep disturbances in Parkinson's disease: the contribution of dopamine in REM sleep regulation. Sleep. Med. Rev. 17, 367-375. doi: 10. 1016/j.smrv/2012.10.006

Lima, M. M., Andersen, M. L., Reksidler, A. B., Vital, M. A., and Tufik, S. (2007). The role of the substantia nigra pars compacta in regulating sleep patterns in rats. PLoS One 2:e513. doi: 10.1371/journal.pone.0000513

Liu, C., Fukuhara, C., Wessel, J. H., Iuvone, P. M., and Tosini, G. (2004). Localization of aa-nat mRNA in the rat retina by fluorescence in situ hybridization and laser capture microdissection. Cell. Tissue Res. 315, 197-201. doi: 10.1007/s00441-003-0822-1

Liu, L. L., Spix, N. J., and Zhang, D. Q. (2017). NMDA receptors contribute to retrograde synaptic transmission from ganglion cell photoreceptors to dopaminergic amacrine cells. Front. Cell. Neurosci. 11:279. doi: 10.3389/fncel. 2017.00279

Liu, S., Plachez, C., Shao, Z., Puche, A., and Shipley, M. T. (2013). Olfactory bulb short axon cell release of GABA and dopamine produces a temporally biphasic inhibition-excitation response in external tufted cells. J. Neurosci. 33, 2916-2926. doi: 10.1523/JNEUROSCI.3607-12.2013

Liu, S., Puche, A. C., and Shipley, M. T. (2016). The interglomerular circuit potently inhibits olfactory bulb output neurons by both direct and indirect pathways. J. Neurosci. 36, 9604-9617. doi: 10.1523/JNEUROSCI.1763-16.2016

Liu, X., Zhang, Z., and Ribelayga, C. P. (2012). Clock proteins among neuronal cell types in mouse retina. PLoS One 7:e50602. doi: 10.1371/journal.pone.0050602

Lizbinski, K. M., and Dacks, A. M. (2018). Intrinsic and extrinsic neuromodulation of olfactory processing. Front. Cell. Neurosci. 11:424. doi: 10.3389/fncel.2017. 00424

Lledo, P. M., Alonso, M., and Grubb, M. S. (2006). Adult neurogenesis and functional plasticity in neuronal circuits. Nat. Rev. Neurosci. 7, 179-193. doi: $10.1038 /$ nrn 1867

Lucas, R. J., Douglas, R. H., and Foster, R. G. (2001). Characterization of an ocular photopigment capable of driving pupillary constriction in mice. Nat. Neurosci. 4, 621-626. doi: 10.1038/88443

Luskin, M. B. (1993). Restricted proliferation and migration of postnatally generated neurons derived from the forebrain subventricular zone. Neuron 11, 173-189. doi: 10.1016/0896-6273(93)90281-u

Ma, K., Han, C., Zhang, G., Guo, X., Xia, Y., Wan, F., et al. (2019). Reduced VMAT2 expression exacerbates the hyposmia in the MPTP model of Parkinson's disease. Biochem. Biophys. Res. Commun. 513, 306-312. doi: 10.1016/j.bbrc.2019. 03.159 
Maher, B. J., and Westbrook, G. L. (2008). Co-transmission of dopamine and GABA in periglomerular cells. J. Neurophysiol. 99, 1559-1564. doi: 10.1152/jn. 00636.2007

Mariani, A. P., and Hokoc, J. N. (1988). Two types of tyrosine hydroxylaseimmunoreactive amacrine cells in the rhesus monkey retina. J. Comp. Neurol. 276, 81-91. doi: 10.1002/cne.902760106

Marin, C., Laxe, S., Langdon, C., Berenguer, J., Lehrer, E., Mariño-Sánchez, F., et al. (2017). Olfactory function in an excitotoxic model for secondary neuronal degeneration: role of dopaminergic interneurons. Neuroscience 364, 28-44. doi: 10.1016/j.neuroscience.2017.09.008

Mazade, R. E., and Eggers, E. D. (2016). Light adaptation alters inner retinal inhibition to shape OFF retinal pathway signaling. J. Neurophysiol. 115, 27612778. doi: 10.1152/jn.00948.2015

Mazade, R. E., Flood, M. D., and Eggers, E. D. (2019). Dopamine D1 receptor activation reduces local inner retinal inhibition to light-adapted levels. J. Neurophysiol. 121, 1232-1243. doi: 10.1152/jn.00448.2018

McGann, J. P. (2013). Presynaptic inhibition of olfactory sensory neurons: new mechanisms and potential functions. Chem. Senses 38, 459-474. doi: 10.1093/ chemse/btj018

McLean, J. H., and Shipley, M. T. (1988). Postmitotic, postmigrational expression of tyrosine hydroxylase in olfactory bulb dopaminergic neurons. J. Neurosci. 8, 3658-3669. doi: 10.1523/JNEUROSCI.08-10-03658.1988

Meir, A., Bell, D. C., Stephens, G. J., Page, K. M., and Dolphin, A. C. (2000). Calcium channel beta subunit promotes voltage-dependent modulation of alpha B 1 by G beta gamma. Biophys. J. 79, 731-746. doi: 10.1016/S0006-3495(00)76331-4

Merkle, F. T., Mirzadeh, Z., and Alvarez-Buylla, A. (2007). Mosaic organization of neural stem cells in the adult brain. Science 317, 381-384. doi: 10.1126/science. 1144914

Miller, J. K., Granados-Fuentes, D., Wang, T., Marpegan, L., Holy, T. E., and Herzog, E. D. (2014). Vasoactive intestinal polypeptide mediates circadian rhythms in mammalian olfactory bulb and olfaction. J. Neurosci. 34, 6040-6046. doi: 10.1523/JNEUROSCI.4713-13.2014

Miller, R. J. (1987). Multiple calcium channels and neuronal functions. Science 235, 46-52. doi: 10.1126/science. 2432656

Mills, S. L., Xia, X. B., Hoshi, H., Firth, S. I., Rice, M. E., Frishman, L. J., et al. (2007). Dopaminergic modulation of tracer coupling in a ganglion-amacrine cell network. Vis. Neurosci. 24, 593-608. doi: 10.1017/S0952523807070575

Missale, C., Nash, S. R., Robinson, S. W., Jaber, M., and Caron, M. G. (1998). Dopamine receptors: from structure to function. Physiol. Rev. 78, 189-225. doi: 10.1152/physrev.1998.78.1.189

Modugno, N., Lena, F., Biasio, F. D., Cerrone, G., Ruggieri, S., and Fornia, F. (2013). A clinical overview of non-motor symptoms in Parkinson's disease. Arch. Ital. Biol. 151, 148-168.

Mohawk, J. A., Green, C. B., and Takahashi, J. S. (2012). Central and peripheral circadian clocks in mammals. Annu. Rev. Neurosci. 35, 445-462. doi: 10.1146/ annurev-neuro-060909-153128

Mundiñano, I. C., Caballero, M. C., Ordóñez, C., Hernandez, M., DiCaudo, C., Marcilla, I., et al. (2011). Increased dopaminergic cells and protein aggregates in the olfactory bulb of patients with neurodegenerative disorders. Acta Neuropathol. 122, 61-74. doi: 10.1007/s00401-011-0830-2

Munteanu, T., Noronha, K. J., Leung, A. C., Pan, S., Lucas, J. A., and Schmidt, T. M. (2018). Light-dependent pathways for dopaminergic amacrine cell development and function. eLife 7:e39866. doi: 10.7554/eLife. 39866

Nagayama, S., Homma, R., and Imamura, F. (2014). Neuronal organization of olfactory bulb circuits. Front. Neural. Circuits 8:98. doi: 10.3389/fncir.2014. 00098

Nguyen-Legros, J. (1988). Functional neuroarchitecture of the retina: hypothesis on the dysfunction of retinal dopaminergic circuitry in Parkinson's disease. Surg. Radiol. Anat. 10, 137-144. doi: 10.1007/bf02307822

Nguyen-Legros, J., Chanut, E., Versaux-Botteri, C., Simon, A., and Trouvin, J. H. (1996). Dopamine inhibits melatonin synthesis in photoreceptor cells through a $\mathrm{D}_{2}$-like receptor subtype in the rat retina: biochemical and histochemical evidence. J. Neurochem. 67, 2514-2520. doi: 10.1046/j.1471-4159. 1996.67062514.x

Nguyen-Legros, J., Simon, A., Caillé, I., and Bloch, B. (1997). Immunocytochemical localization of dopamine $\mathrm{D}_{1}$ receptors in the retina of mammals. Vis. Neurosci. 14, 545-551. doi: 10.1017/s0952523800012207
Nickell, W. T., Behbehani, M. M., and Shipley, M. T. (1994). Evidence for GABABmediated inhibition of transmission from the olfactory nerve to mitral cells in the rat olfactory bulb. Brain. Res. Bull. 35, 119-123. doi: 10.1016/0361-9230(94) 90091-4

Nir, I., and Iuvone, P. M. (1994). Alterations of light-evoked dopamine metabolism in dystrophic retinas of mutant rds mice. Brain Res. 649, 85-94. doi: 10.1016/ 0006-8993(94)91051-0

Nir, I., Haque, R., and Iuvone, P. M. (2000a). Diurnal metabolism of dopamine in the mouse retina. Brain Res. 870, 118-125. doi: 10.1016/s0006-8993(00) 02409-4

Nir, I., Haque, R., and Iuvone, P. M. (2000b). Diurnal metabolism of dopamine in dystrophic retinas of homozygous and heterozygous retinal degeneration slow (rds) mice. Brain Res. 884, 13-22. doi: 10.1016/s0006-8993(00) 02855-9

Nir, I., Harrison, J. M., Haque, R., Low, M. J., Grandy, D. K., Rubinstein, M., et al. (2002). Dysfunctional light-evoked regulation of cAMP in photoreceptors and abnormal retinal adaptation in mice lacking dopamine D4 receptors. J. Neurosci. 22, 2063-2073. doi: 10.1523/jneurosci.22-06-020 63.2002

Nowycky, M. C., Halász, N., and Shepherd, G. M. (1983). Evoked field potential analysis of dopaminergic mechanisms in the isolated turtle olfactory bulb. Neuroscience 8, 717-722. doi: 10.1016/0306-4522(83)90005-2

O’Brien, J. J., Chen, X., Macleish, P. R., O'Brien, J., and Massey, S. C. (2012). Photoreceptor coupling mediated by connexin36 in the primate retina. J. Neurosci. 32, 4675-4687. doi: 10.1523/JNEUROSCI.4749-11.2012

Onofrj, M., and Bodis-Wollner, I. (1982). Dopaminergic deficiency causes delayed visual evoked potentials in rats. Ann. Neurol. 11, 484-490. doi: 10.1002/ana. 410110508

Parrish-Aungst, S., Shipley, M. T., Erdelyi, F., Szabo, G., and Puche, A. C. (2007). Quantitative analysis of neuronal diversity in the mouse olfactory bulb. J. Comp. Neurol. 501, 825-836. doi: 10.1002/cne.21205

Panzanelli, P., Fritschy, J. M., Yanagawa, Y., Obata, K., and Sassoe-Pognetto, M. (2007). GABAergic phenotype of periglomerular cells in the rodent olfactory bulb. J. Comp. Neurol. 502, 990-1002. doi: 10.1002/cne.21356

Peppe, A., Stanzione, P., Pierantozzi, M., Semprini, R., Bassi, A., Santilli, A. M., et al. (1998). Does pattern electroretinogram spatial tuning alteration in Parkinson's disease depend on motor disturbances or retinal dopaminergic loss? Electroencephalogr. Clin. Neurophysiol. 106, 374-382. doi: 10.1016/s00134694(97)00075-8

Pérez-Fernández, V., Milosavljevic, N., Allen, A. E., Vassey, K. A., Jobling, A. I., Fletcher, E. L., et al. (2019). Rod photoreceptor activation alone defines the release of dopamine in the retina. Curr. Biol. 29, 763-774. doi: 10.1016/j. cub2019.01.042

Perk, C. G., and Mercer, A. R. (2006). Dopamine modulation of honey bee (Apis mellifera) antennal-lobe neurons. J. Neurophysiol. 95, 1147-1157. doi: 10.1152/ jn/01220.2004

Pignatelli, A., Ackman, J. B., VIgetti, D., Beltrami, A. P., Zucchini, S., and Bellizzu, O. (2009). A potential reservoir of immature dopaminergic replacement neurons in the adult mammalian olfactory bulb. Pflugers. Arch. 457, 899-915. doi: 10.1007/s00424-008-0535-0

Pignatelli, A., Borin, M., Iseppe, A. F., Gambardella, C., and Belluzzi, O. (2013). The h-current in periglomerular dopaminergic neurons of the mouse olfactory bulb. PLoS One 8:e56571. doi: 10.1371/journal.pone.0056571

Pignatelli, A., Kobayashi, K., Okano, H., and Belluzzi, O. (2005). Functional properties of dopaminergic neurones in the mouse olfactory bulb. J. Physiol. 564, 501-514. doi: 10.1113/jphysiol.2005.084632

Ponsen, M. M., Stoffers, D., Booij, J., van Eck-Smit, B. L. F., Wolters, E., and Berendse, H. W. (2004). Idiopathic hyposmia as a preclinical sign of Parkinson's disease. Ann. Neurol. 56, 173-181. doi: 10.1002/ana.20160

Price, M. J., Feldman, R. G., Adelberg, D., and Kayne, H. (1992). Abnormalities in color vision and contrast sensitivity in Parkinson's disease. Neurology 42, 887-890. doi: 10.1212/wnl.42.4.887

Prigge, C. L., Yeh, P. T., Liou, N. F., Lee, C. C., You, S. F., Liu, L. L., et al. (2016). M1 ipRGCs influence visual function through retrograde signaling in the retina. J. Neurosci. 36, 7184-7197. doi: 10.1523/JNEUROSCI.3500-15.2016

Pringsheim, T., Jette, N., Frolkis, A., and Steeves, T. D. (2014). The prevalence of Parkinson's disease: a systematic review and meta-analysis. Mov. Disord. 29, 1583-1590. doi: $10.1002 / \mathrm{mds} .25945$ 
Puche, A. C., and Shipley, M. T. (1999). Odor-induced, activity-dependent Transneuronal gene induction in vitro: mediation by NMDA receptors. J. Neurosci. 19, 1359-1370. doi: 10.1523/JNEUROSCI.19-04-01359.1999

Puopolo, M., Bean, B. P., and Raviola, E. (2005). Spontaneous activity of isolated dopaminergic periglomerular cells of the main olfactory bulb. J. Neurophysiol. 94, 3618-3627. doi: 10.1152/jn.00225.2005

Puopolo, M., Hochstetler, S. E., Gustincichm, S., Wightman, R. M., and Raviola, E. (2001). Extrasynaptic release of dopamine in a retinal neuron: activity dependence and transmitter modulation. Neuron 30, 211-225. doi: 10.1016/ s0896-6273(01)00274-4

Ribelayga, C., and Mangel, S. C. (2003). Absence of circadian clock regulation of horizontal cell gap junctional coupling reveals two dopamine systems in the goldfish retina. J. Comp. Neurol. 467, 243-253. doi: 10.1002/cne.10927

Ribelayga, C., Cao, Y., and Mangel, S. C. (2008). The circadian clock in the retina controls rod-cone coupling. Neuron 59, 790-801. doi: 10.1016/j.neuron.2008. 07.017

Ribelayga, C., Wang, Y., and Mangel, S. C. (2004). A circadian clock in the fish retina regulates dopamine release via activation of melatonin receptors. J. Physiol. 554(Pt 2), 467-482. doi: 10.1113/jphysiol.2003.053710

Rodrigues, L. S., Targa, A. D. S., Noseda, A. C. D., Aurich, M. F., Cunha, C. D., and Lima, M. M. S. (2014). Olfactory impairment in the rotenone model of Parkinson's disease is associated with bulbar dopaminergic D2 activity after REM sleep deprivation. Front. Cell. Neurosci. 8:383. doi: 10.3389/fncel/2014. 00383

Roy, S., and Field, G. D. (2019). Dopaminergic modulation of retinal processing from starlight to sunlight. J. Pharmacol. Sci. 140, 86-93. doi: 10.1016/j.jphs. 2019.03.006

Ruan, G. X., Allen, G. C., Yamazaki, S., and McMahon, D. G. (2008). An autonomous circadian clock in the inner mouse retina regulated by dopamine and GABA. PLoS Biol. 6:e249. doi: 10.1371/journal.pbio.0060249

Ruan, G. X., Zhang, D. Q., Zhou, T., Yamazaki, S., and McMahon, D. G. (2006). Circadian organization of the mammalian retina. Proc. Natl. Acad. Sci. U.S.A. 103, 9703-9708. doi: 10.1073/pnas.0601940103

Sakamoto, K., Liu, C., and Tosini, G. (2004). Circadian rhythms in the retina of rats with photoreceptor degeneration. J. Neurochem. 90, 1019-1024. doi: 10.1111/j.1471-4159.2004.02571.x

Sakamoto, K., Liu, C., Kasamatsu, M., Pozdeyev, N. V., Iuvone, P. M., and Tosini, G. (2005). Dopamine regulates melanopsin mRNA expression in intrinsically photosensitive retinal ganglion cells. Eur. J. Neurosci. 22, 3129-3136. doi: 10. $1111 / j .1460-9568.2005 .04512 . x$

Sancandi, M., Schul, E. V., Economides, G., Constanti, A., and Mercer, A. (2018). Structural changes observed in the piriform cortex in a rat model of pre-motor Parkinson's disease. Front. Cell. Neurosci. 12:479. doi: 10.3389/fncel.2018.00479

Sawada, M., Kaneko, N., Inada, H., Wake, H., Kato, Y., Yanagawa, Y., et al. (2011). Sensory input regulates spatial and subtype-specific patterns of neuronal turnover in the adult olfactory bulb. J. Neurosci. 31, 11587-11596. doi: 10.1523/ JNEUROSCI.0614-11.2011

Sayin, S., Boehm, A. C., Kobler, J. M., De Backer, J. F., and Grunwalk Kadow, I. C. (2018). Internal state dependent odor processing and perception - the role of neuromodulation in the fly olfactory system. Front. Cell. Neurosci. 12:11. doi: $10.3389 /$ fncel.2018.00011

Shulman, L. M., and Fox, D. A. (1996). Dopamine inhibits mammalian photoreceptor $\mathrm{Na}+\mathrm{K}+$-ATPase activity via a selective effect on the alpha3 isozyme. Proc. Natl. Acad. Sci. U.S.A. 93, 8034-8039. doi: 10.1073/pnas.93.15. 8034

Smith, B. J., Côté, P. D., and Tremblay, F. (2015). D1 dopamine receptors modulate cone ON bipolar cell Nav channels to control daily rhythms in photopic vision. Chronobiol. Int. 32, 48-58. doi: 10.3109/07420528.2014.951054

Smith, R. L., Baker, H., and Greer, C. A. (1993). Immunohistochemical analyses of the human olfactory bulb. J. Comp. Neurol. 333, 519-530. doi: 10.1002/cne. 903330405

Tagliati, M., Bodis-Wollner, I., and Yahr, M. D. (1996). The pattern electroretinogram in Parkinson's disease reveals lack of retinal spatial tuning. Electroencephalogr. Clin. Neurophysiol. 100, 1-11. doi: 10.1016/0168-5597(95)00169-7

Tauchi, M., Madigan, N. K., and Masland, R. H. (1990). Shapes and distributions of the catecholamine-accumulating neurons in the rabbit retina. J. Comp. Neurol. 293, 178-189. doi: 10.1002/cne/902930203
Taylor, T. N., Caudle, W. M., Shepherd, K. R., Noorian, A., Jackson, C. R., Iuvone, P. M., et al. (2009). Nonmotor symptoms of Parkinson's disease revealed in an animal model with reduced monoamine storage capacity. J. Neurosci. 29, 8103-8113. doi: 10.1523/JNEUROSCI.1495-09.2009

Tessier-Lavigne, M., and Attwell, D. (1988). The effect of photoreceptor coupling and synapse nonlinearity of signal:noise ratio in early visual processing. Proc. $R$. Soc. Long. B Biol. Sci. 234, 171-197. doi: 10.1098/rspb.1988.0043

Tillerson, J. L., Caudle, W. M., Parent, J. M., Gong, C., Schallert, T., and Miller, G. W. (2006). Olfactory discrimination deficits in mice lacking the dopamine transported or the D2 dopamine receptor. Behav. Brain. Res. 172, 97-105. doi: 10.1016/j.bbr.2006.04.025

Tosini, G., and Dirden, J. C. (2000). Dopamine inhibits melatonin release in the mammalian retina: in vitro evidence. Neurosci. Lett. 286, 119-122. doi: 10.1016/ s0304-3940(00)01117-4

Tosini, G., and Menaker, M. (1996). Circadian rhythms in cultured mammalian retina. Science 272, 419-421. doi: 10.1126/science.272.5260.419

Tosini, G., and Menaker, M. (1998). The clock in the mouse retina: melatonin synthesis and photoreceptor degeneration. Brain Res. 789, 221-228. doi: 10. 1016/s0006-8993(97)01446-7

Tosini, G., Pozdeyev, N., Sakamoto, K., and Iuvone, P. M. (2008). The circadian clock system in the mammalian retina. Bioessays 30, 624-633. doi: 10.1002/bies. 20777

Trombley, P. Q., and Westbrook, G. L. (1990). Excitatory synaptic transmission in cultures of rat olfactory bulb. J. Neurophysiol. 64, 598-606. doi: 10.1152/jn.1990. 64.2.598

Umino, O., and Dowling, J. E. (1991). Dopamine release from interplexiform cells in the retina: effects of GnRH, FMRFamide, bicuculline, and enkephalin on horizontal cell activity. J. Neurosci. 11, 3034-3046. doi: 10.1523/JNEUROSCI. 11-10-03034.1991

Urwyler, P., Nef, T., Killen, A., Collerton, D., Thomas, A., Burn, D., et al. (2014). Visual complaints and visual hallucinations in Parkinson's disease. Parkinsonims. Relat. Disord. 20, 318-322. doi: 10.1016/j.parkreldis.2013.12.009

Vaaga, C. E., Yorhason, J. T., Williams, J. T., and Westbrook, G. L. (2017). Presynaptic gain control by endogenous cotransmission of dopamine and GABA in the olfactory bulb. J. Neurophysiol. 117, 1163-1170. doi: 10.1152/jn. 00694.2016

Van Hook, M. J., Wong, K. Y., and Berson, D. M. (2012). Dopaminergic modulation of ganglion-cell photoreceptors in rat. Eur. J. Neurosci. 35, 507-518. doi: 10. 1111/j.1460-9568.2011.07975.x

Versaux-Botteri, C., Martin-Martinelli, E., Nguyen-Legros, J., Geffard, M., Vigny, A., and Denoroy, L. (1986). Regional specialization of the rat retina: catecholamine-containing amacrine cell characterization and distribution. J. Comp. Neuro 243, 422-433. doi: 10.1002/cne.902430311

Versaux-Botteri, C., Nguyen-Legros, J., Vigny, A., and Raoux, N. (1984). Morphology, density and distribution of tyrosine hydroxylase-like immunoreactive cells in the retina of mice. Brain Res. 301, 192-197. doi: 10.1016/0006-8993(84)90423-2

Veruki, M. L., and Wässle, H. (1996). Immunohistochemical localization of dopamine $\mathrm{D}_{1}$ receptors in rat retina. Eur. J. Neurosci. 8, 2286-2297. doi: 10. $1111 /$ j.1460-9568.1996.tb01192.x

Wachowiak, M., McGann, J. P., Heyward, P. M., Shao, Z., Puche, A. C., and Shipley, M. T. (2005). Inhibition [Corrected] of olfactory receptor neuron input to olfactory bulb glomeruli mediated by suppression of presynaptic calcium influx. J. Neurophysiol. 94, 2700-2712. doi: 10.1152/jn.00286.2005

Wang, H. H., Cuenca, N., and Kolb, H. (1990). Development of morphological types and distribution patterns of amacrine cells immunoreactive to tyrosine hydroxylase in the cat retina. Vis. Neurosci. 4, 159-175. doi: 10.1017/ s0952523800002315

Wang, Y., Harsanyi, K., and Mangel, S. C. (1997). Endogenous activation of dopamine $\mathrm{D}_{2}$ receptors regulates dopamine release in the fish retina. J. Neurophysiol. 78, 439-449. doi: 10.1152/jn.1997.78.1.439

Weber, A. M., Wong, F. K., Tufford, A. R., Schlichter, L. C., Matveev, V., and Stanley, E. F. (2010). N-type $\mathrm{Ca}^{2+}$ channels carry the largest current: implications for nanodomains and transmitter release. Nat. Neurosci. 13, 13481350. doi: 10.1038/nn.2657

Weil, R. S., Schrag, A. E., Warren, J. D., Crutch, S. J., Lees, A. J., and Morris, H. R. (2016). Visual dysfunction in Parkinson's disease. Brain 139, 2827-2843. doi: 10.1093/brain/aww175 
Whitman, M. C., and Greer, C. A. (2007). Adult-generated neurons exhibit diverse development fates. Dev. Neurobiol. 67, 1079-1093. doi: 10.1002/dneu.20389

Wilson, D. A., and Sullivan, R. M. (1995). The D2 antagonist spiperone mimics the effects of olfactory deprivation on mitral/tufted cell odor response patterns. J. Neurosci. 15, 5574-5581. doi: 10.1523/JNEUROSCI.15-08-05574.1995

Wilson, D. A., and Wood, J. G. (1992). Functional consequences of unilateral olfactory deprivation: time-course and age sensitivity. Neuroscience 49, 183 192. doi: 10.1016/0306-4522(92)90086-h

Witkovsky, P. (2004). Dopamine and retinal function. Doc. Ophthalmol. 108, 17-40. doi: 10.1023/b:doop.0000019487.88486.0a

Witkovsky, P., Gabriel, R., Haycock, J. W., and Meller, E. (2000). Influence of light and neural circuitry on tyrosine hydroxylase phosphorylation in the rat retina. J. Chem. Neuroanat. 19, 105-116. doi: 10.1016/s0891-0618(00)00055-7

Witkovsky, P., Veisenberger, E., Haycock, J. W., Akopian, A., Garcia-Espana, A., and Meller, E. (2004). Activity-dependent phosphorylation of tyrosine hydroxylase in dopaminergic neurons of the rat retina. J. Neurosci. 24, 42424249. doi: 10.1523/JNEUROSCI.5436-03.2004

Witkovsky, P., Veisenberger, E., LeSauter, J., Yan, L., Johnson, M., Zhang, D. Q., et al. (2003). Cellular location and circadian rhythm expression of the biological clock gene Period1 in the mouse retina. J. Neurosci. 23, 7670-7676. doi: 10. 1523/jneurosci.23-20-07670.2003

Wong, J. C. Y., Smyllie, N. J., Banks, G. T., Pothecary, C. A., Barnard, A. R., Maywood, E. S., et al. (2018). Differential roles for cryptochromes in the mammalian retinal clock. FASEB J. 32, 4302-4314. doi: 10.1096/fj. 201701165RR

Winkler, A. S., Landau, S., and Chaudhuri, K. R. (2002). Serum prolactin levels in Parkinson's disease and multiple system atrophy. Clin. Auton. Res. 12, 393-398. doi: 10.1007/s10286-002-0025-y

Wulle, I., and Schnitzer, J. (1989). Distribution and morphology of tyrosine hydroxylase-immunoreactive neurons in the developing mouse retina. Brain. Res. Dev. Brain. Res. 48, 59-72. doi: 10.1016/0165-3806(89)90093-x

Wulle, I., and Wagner, H. J. (1990). GABA and tyrosine hydroxylase immunocytochemistry reveal different patterns of colocalization in retinal neurons of various vertebrates. J. Comp. Neurol. 296, 173-178. doi: 10.1002/ cne.902960111

Yan, W., Laboulaye, M. A., Tran, N. M., Whitney, I. E., Benhar, I., and Sanes, J. R. (2020). Mouse retinal cell atlas: molecular identification of over sixty cell types. J. Neurosci. 40, 5177-5195. doi: 10.1523/JNEUROSCI.04 71-20.2020

Yin, N., Yang, Y. L., Cheng, S., Wang, H. N., Hu, X., Mia, Y., et al. (2020). Dopamine $\mathrm{D}_{2}$ receptor-mediated modulation of rat retinal ganglion cell excitability. Neurosci. Bull. 36, 230-242. doi: 10.1007/s12264-019-00431-3

Yujnovsky, I., Hirayama, J., Doi, M., Borrelli, E., and Sassone-Corsi, P. (2006). Signaling mediated by the dopamine $\mathrm{D}_{2}$ receptor potentiates circadian regulation by CLOCK:BMAL1. Proc. Natl. Acad. Sci. U.S.A. 103, 6386-6391. doi: 10.1073/pnas.0510691103

Zhang, A. J., Jacoby, R., and Wu, S. M. (2011). Light- and dopamine-regulated receptive field plasticity in primate horizontal cells. J. Comp. Neurol. 519, 2125-2134. doi: 10.1002/cne.22604

Zhang, D. Q., Belenky, M. A., Sollars, P. J., Pickard, G. E., and McMahon, D. G. (2012). Melanopsin mediates retrograde visual signaling in the retina. PLoS One 7:e42647. doi: 10.1371/journal.pone.0042647

Zhang, D. Q., Stone, J. F., Zhou, T., Ohta, H., and McMahon, D. G. (2004). Characterization of genetically labeled catecholamine neurons in the mouse retina. Neuroreport 15, 1761-1765. doi: 10.1097/01.wnr.0000135699.75 775.41

Zhang, D. Q., Wong, K. Y., Sollars, P. J., Berson, D. M., Pickard, G. E., and McMahon, D. G. (2008). Intraretinal signaling by ganglion cell photoreceptors to dopaminergic amacrine neurons. Proc. Natl. Acad. Sci. U.S.A. 105, 1418114186. doi: 10.1073/pnas.0803893105

Zhang, D. Q., Zhou, T. R., and McMahon, D. G. (2007). Functional heterogeneity of retinal dopaminergic neurons underlying their multiple roles in vision. J. Neurosci. 27, 692-699. doi: 10.1523/JNEUROSCI.4478-06.2007

Conflict of Interest: The authors declare that the research was conducted in the absence of any commercial or financial relationships that could be construed as a potential conflict of interest.

Copyright (c) 2020 Korshunov, Blakemore and Trombley. This is an open-access article distributed under the terms of the Creative Commons Attribution License (CC BY). The use, distribution or reproduction in other forums is permitted, provided the original author(s) and the copyright owner(s) are credited and that the original publication in this journal is cited, in accordance with accepted academic practice. No use, distribution or reproduction is permitted which does not comply with these terms. 